\title{
Simplification of the representation of the organic component of atmospheric particulates
}

\author{
Gordon McFiggans,* M. Rami Alfarra, James Allan, Keith Bower, Hugh Coe, \\ Mike Cubison, Dave Topping, Paul Williams, Stefano Decesari, Cristina Facchini and \\ Sandro Fuzzi
}

Atmospheric Science Group, University of Manchester, PO Box 88, Sackville Street, Manchester, UK, M60 1QD

Received 4th January 2005, Accepted 7th February 2005
First published as an Advance Article on the web 12th May 2005

We present an analysis of recent field data to investigate the variation in the organic component of atmospheric aerosol and its behaviour in the moist environment. In all locations the degree of oxygenation of the organic material increases with photochemical age, as does the particulate hygroscopicity. These changes will generally occur in spatial scales comparable to a single cell in global models at representative boundary layer wind speeds. Using ADDEM, a new model of the equilibrium state of multicomponent aerosol, we show that inorganic component changes must be responsible for the increase in particulate hygroscopicity with photochemical age. It is suggested that a common representation of nearfield and background organic aerosol composition is sufficient to describe the behaviour of organic components in a variety of field experiments; nearfield small mode organics being dominated by a combustion-derived unoxidised signature, whilst the background accumulation mode is more oxygenated and dominates in air masses with a photochemical age of more than a couple of days. This representation may be used within the sub-saturated regime to predict the behaviour of ambient particulates in the moist atmosphere. Whether a similar common representation can be used for cloud activation prediction in supersaturated environments, or for investigation of gas-to-particle partitioning, should be investigated.

\section{Background}

Tropospheric particulates contain a significant and variable fraction of organic material, ranging from $10 \%$ to $70 \%$ of the fine particulate mass. ${ }^{1-6}$ The importance of this component in climate forcing, ${ }^{7}$ on human health ${ }^{8}$ and in bio-geochemical cycling ${ }^{9}$ is poorly understood; hence concerted recent effort has recently been made to investigate and quantify the role of organics in the tropospheric aerosol. Directly related to the poor knowledge of the identity of the organic components, major uncertainties exist in understanding the detailed roles of atmospheric processes on the aerosol composition, of multicomponent aerosol property and behaviour modification and in predicting the effects of the particulates on climatically important processes.

In contrast to the inorganic component of atmospheric aerosol, the organic fraction comprises hundreds of individual compounds of both natural and anthropogenic origin covering a wide range of molecular forms, solubility, reactivity and physical properties. ${ }^{10}$ Field studies indicate that 
$20-70 \%$ of condensed phase organic carbon is water soluble ${ }^{11,12}$ and includes low molecular weight carboxylic acids, dicarboxylic acids, alcohols, aldehydes, ketones, nitrates and multifunctional compounds. ${ }^{13}$ Analysing the water solubility, condensability and atmospheric abundance, Saxena and Hildemann ${ }^{11}$ proposed that this fraction could also include $\mathrm{C}_{2}-\mathrm{C}_{7}$ polyols, amino acids and other oxygenated multifunctional compounds. Significant quantities of organic nitrates, nitrophenols and polynuclear aromatic compounds have also been isolated. Major difficulties remain in performing a comprehensive characterisation of the large number of individual compounds and only $10-15 \%$ of the total organic aerosol mass has ever been identified at a molecular level. ${ }^{3,14}$ Besides problems associated with conventional impactor sampling (including inevitable coarse temporal and size averaging and problems associated with post-sampling transformation of the bulk material), the sheer number of isolated, but as yet unattributed, compounds leads to current insurmountable difficulties in interpretation and prediction of aerosol properties using such approaches in isolation. It is questionable whether such approaches employed in sampling and offline analyses will ever yield a useful representation for ready interpretation of the contribution of organics to atmospheric aerosol behaviour. Much of the difficulty of isolating and identifying the vast array of individual organic aerosol components may be attributed to the fact that highmolecular weight organic (i.e. $>\mathrm{C}_{40}$ ) and highly polar compounds cannot be analysed with standard GC/MS methods. In addition, some organic compounds are not easily extracted or their GC/MS signatures cannot be confirmed by standards. ${ }^{3,11}$ However, water-soluble macromolecular substances with spectroscopic signature and functional composition similar to "humic-like substances" (HULIS) have recently been found to contribute $20-50 \%$ to the water-soluble fraction of organic aerosol at urban and rural sites in Europe. ${ }^{15-19}$ These substances are composed of hundreds of different molecules, which cannot be separated, and therefore cannot be individually identified and quantified. ${ }^{19}$ Limbeck et al. ${ }^{20}$ stated that primary sources such as biomass burning, cannot explain their observed levels in Europe, and demonstrated condensed phase macromolecule formation by heterogeneous reaction of isoprene or $\alpha$-pinene in the presence of a sulfuric acid aerosol catalyst. In addition, recent chamber studies have reported the formation of macromolecules in organic aerosol produced from the photooxidation of anthropogenic and biogenic precursors. $^{21,22}$ The presence and characterisation of HULIS in aerosol samples have been investigated using a number of methods. Krivacsy et al. ${ }^{19}$ reported that in alkaline solutions, these compounds are ionic and capillary electrophoresis can indicate their presence in samples. Infrared spectroscopy has been widely used for their characterisation in atmospheric samples ${ }^{15,20,23}$ and indicate that carboxylic $(\mathrm{COOH})$, hydroxyl $(\mathrm{OH})$ and carbonyl groups $(\mathrm{C}=\mathrm{O})$ are the main functional groups of these macromolecular organic aerosol components. The macromolecular contribution to particulate mass is not only from HULIS; proteins and their free amino-compound derivatives have been found to contribute up to around $10 \%$ fog water and $\mathrm{PM}_{2.5}$ WSOC mass. ${ }^{24}$ These compounds cannot be formed from in situ production and indicate that particulate macromolecular material is at least in part of primary origin.

A specific key property of particulates, important to all major potential aerosol impacts, is their behaviour in the moist ambient atmosphere and organic compounds have the potential to influence this behaviour. Direct radiative forcing is critically dependent on the precise sizes of subsaturated ambient aerosol particles, and cloud activation is determined solely by the ability of a particle to take on water in a supersaturated environment. Human health effects of particulates are largely dependent on their respirability, which in turn depends on the penetration depth in the lung. Those particles which take up less water in the moist environment may penetrate deeper and become deposited in the alveolar region. An aerosol particle's affinity for water may be expressed as its growth factor $\left(\mathrm{GF}_{\mathrm{D}}\right)$ in changing its environment from dry to a fixed relative humidity. The $\mathrm{GF}_{\mathrm{D}}$ can be measured in the real atmosphere using a hygroscopicity tandem differential mobility analyser (HTDMA). ${ }^{25,26}$ Observations of particle hygroscopicity, coupled with chemical analyses, suggest a range of effects of organic components in both sub- and supersaturated environments. It is seldom possible to explain observed hygroscopicity through the consideration of inorganic components alone and organic compounds may significantly influence particle hygroscopicity. HTDMA field studies have indicated that organics can hinder or enhance water uptake. ${ }^{27,28}$ Laboratory studies have mostly focused on carboxylic acids, di-carboxylic acids and multifunctional organic acids ${ }^{13,29-31}$ and their combinations with inorganic salts, ${ }^{29,32-34}$ though limited HTDMA laboratory studies of macromolecular compounds have been carried out on humic acid ${ }^{35}$ and protein ${ }^{36}$ standards in 
isolation and combined with inorganic compounds. There is no general consensus on the effect of the wide range of organic compounds on hygroscopicity and the effects depends not only on the specific organic components but also on particle morphology and chemistry. ${ }^{33}$

This paper describes the application of the recently developed Aerosol Diameter Dependent Equilibrium Model, ADDEM ${ }^{37,38}$ to interpret data from the first experiment of the UK NERCfunded Tropospheric ORganic CHemistry $(\mathrm{TORCH})$ project. ADDEM requires temperature, relative humidity and aerosol size and composition input and may be used to predict the activities and equilibrium vapour pressures of all components. By use of the water activity prediction under a given set of conditions, ADDEM can predict the equilibrium size of the aerosol particle at any given humidity. We briefly introduce the measurement strategy employed during TORCH 1 and discuss the relevant data collected. We then describe use of these data to initialise ADDEM and compare the result with HTDMA GF ${ }_{\mathrm{D}}$ measured during the project. The results are discussed in terms of the relative importance of inorganic and organic aerosol components and in terms of the simplification of the composition of the aerosol organic fraction.

Despite the overwhelming variety of organic aerosol species and the range of their individual properties, evidence from tropospheric field observations indicate that atmospheric situations may be grouped into a relatively small number of representative scenarios reflecting emission patterns, chemistry and meteorology. We describe the use of an Aerodyne Aerosol Mass Spectrometer (AMS) (Aerodyne Research Inc., Billerica, MA, USA) to provide insights into such behaviour with respect to organic particulate matter. This suggests that aerosol complexity reduction by abstraction from detailed speciation (analogous to that possible in gas phase mechanism reduction) should be possible, depending on the criterion for simplification. To enable reasonable description in detailed process models and ultimately larger scale atmospheric models, the abstraction from known detailed composition must be such that the accuracy and predictive capability of such models will be preserved, particularly with respect to important aerosol properties such as hygroscopicity. The organic aerosol characterisation from the TORCH experiment is examined in the context of the findings from other field projects and interpreted in terms of the proposed simplified description of aerosol organics with respect to hygroscopicity.

\section{Methodology and results}

\section{Aerosol sampling and analysis during the first TORCH experiment}

The aims of the experimental part of the TORCH project were to characterise the gaseous and particulate organic components in a variety of air masses and to investigate processes determining organic partitioning. Two experiments were conducted; the first relatively close to a strong urban source region and the second at a more remote rural location. We focus on the first experiment, conducted in the grounds of Writtle Agricultural College, a semi-rural but urban-influenced location approximately $30 \mathrm{~km}$ north east of London (see Fig. 1), between 30th July and 1st September 2003. A wide range of instrumentation was employed to characterise the trace gas and aerosol composition in a range of air masses. Gas phase measurements will not be discussed here.

The instrumentation for sub-micrometre aerosol measurement was located in a shipping container at the foot of a $10 \mathrm{~m}$ scaffold tower. Air was drawn down a $150 \mathrm{~mm}$ bore, $12 \mathrm{~m}$ high sampling stack at a flow rate of $1501 \mathrm{~min}^{-1}$. The flow rate was such that diffusional losses for sub-micrometre particles were minimal above $5 \mathrm{~nm}$ diameter. Air was sub-sampled isokinetically from the main stack through a $40 \mathrm{~mm}$ bore stainless steel line, bending with a $1 \mathrm{~m}$ radius of curvature then running the full length of the container. A variety of instrumentation further sub-sampled isokinetically from the $40 \mathrm{~mm}$ tube.

A differential mobility particle sizer (DMPS) system comprising two Vienna type differential mobility analysers (DMAs), ${ }^{39}$ one TSI model 3025 condensation particle counter (CPC) and one TSI model 3010 CPC, using volumetric flow control with sheath to aerosol flow ratio of $10: 1$ occupied the first sub-sampling location and was used to measure aerosol number distributions from $3 \mathrm{~nm}$ to $700 \mathrm{~nm}$ diameter.

An HTDMA comprising a humidifier (using a controlled counterflow of sample air and humidified sheath air across a series of Goretex membrane tubes) situated between two identical Vienna type DMAs sub-sampled immediately downstream of the DMPS. The instrument, described 


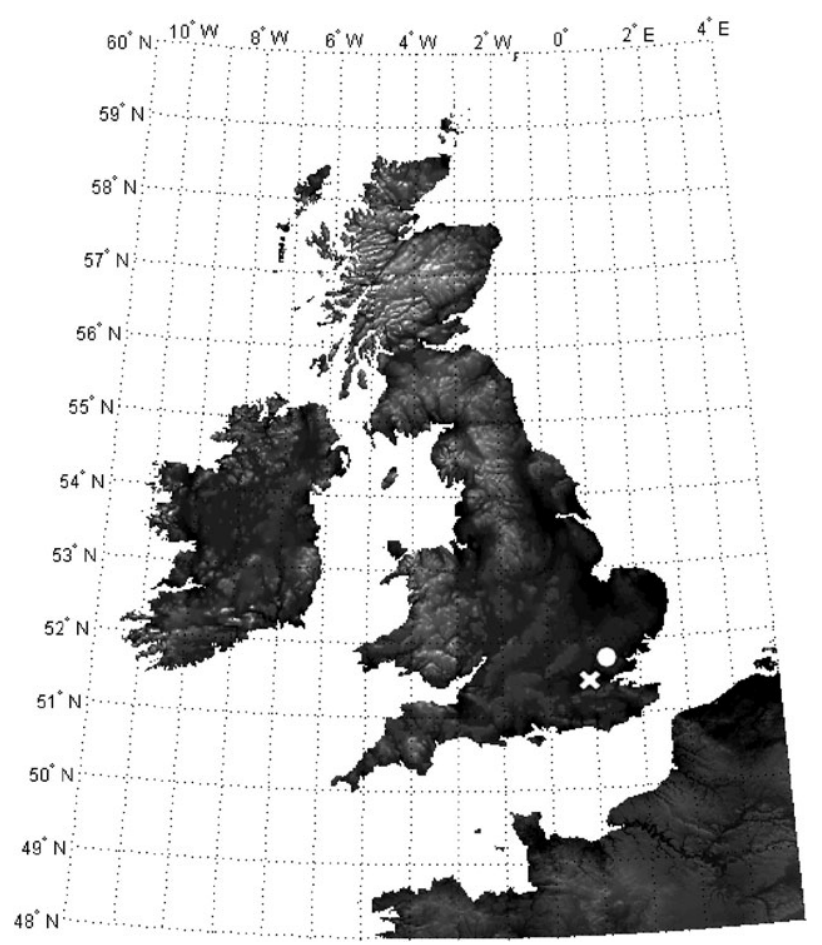

Fig. 1 Location of the first field experiment in the tropospheric organic chemistry project (TORCH 1) at Writtle agricultural college (filled circle) $30 \mathrm{~km}$ north east of London (cross).

in Cubison et al. ${ }^{26}$ was operated in two modes: (i) the first DMA cycled hourly through six dry diameters $(27 \mathrm{~nm}, 40 \mathrm{~nm}, 60 \mathrm{~nm}, 89 \mathrm{~nm}, 137 \mathrm{~nm}, 217 \mathrm{~nm}$ and $360 \mathrm{~nm})$, with the second DMA stepping from $20 \mathrm{~nm}$ to around $750 \mathrm{~nm}$ at a fixed degree of humidification (nominally $90 \%$ ) and (ii) a smaller number of these dry sizes were selected for sizing with various stepped humidities to build up humidograms, plotting $G_{D}$ variation with humidity. The second mode is time-consuming so was performed only at each air mass change to maintain an almost continuous time series for the first mode. Cubison et al $^{26}$ present a new inversion algorithm for obtaining $\mathrm{GF}_{\mathrm{D}}$ distributions from HTDMAs that takes account of the inherent measurement uncertainties and instrument functions and delivers optimally separated $\mathrm{GF}_{\mathrm{D}}$ estimates.

An AMS was used to provide on-line quantitative measurements of the chemical composition and size distributions of the non-refractory fraction of submicrometre aerosol particles (approximately $\mathrm{PM}_{1.0}$ ) and occupied the third sub-sampling location. Little detail of the AMS and principle of operation is given here, a full general description can be found in the literature, ${ }^{40-43}$ as can specific detail concerning its capability of measuring organic material. ${ }^{44}$ Briefly, the sub-micrometre particles in the sampled atmospheric air are focussed into a beam using an aerodynamic lens. The beam is aligned to pass through a skimmer, a chopper, the particle-sizing chamber $(39.5 \mathrm{~cm}$ length $)$ and an aperture, before finally impacting on a heated surface (normally to $550{ }^{\circ} \mathrm{C}$ ). After flash vaporisation of the non-refractory (volatile and semi-volatile) particle components, the vapour is ionised using $70 \mathrm{eV}$ electron impaction. The resulting positive ions are analysed using a quadrupole mass spectrometer (QMA 410, Balzers, Liechtenstein) and detected with a calibrated electron multiplier. In typical field operation, the AMS alternates between two modes: (i) using the aerosol time-of-flight (ToF) mode the mass of key chemical components can be resolved as a function of the vacuum aerodynamic diameter of the particles $\left(\mathrm{dM} / \mathrm{d}_{\log } \mathrm{D}_{\mathrm{va}}\right)$, (ii) in the mass-spectrum (MS) mode the averaged chemical composition of the non-refractory aerosol ensemble is determined by scanning the mass spectrum with the quadrupole mass spectrometer, without size resolved information. 
Finally, a scanning mobility particle sizing (SMPS) system provided with a controllable heated inlet cycling from ambient to $130{ }^{\circ} \mathrm{C}$ and $300{ }^{\circ} \mathrm{C}$ was used to determine the volatile fraction of the aerosol population as a function of size.

Particle distributions from $0.3 \mu \mathrm{m}$ to $47 \mu \mathrm{m}$ diameter were measured at the top of the scaffold tower using two commercial optical instruments. The Grimm model 1.109 optical particle counter (OPC) retrieved distributions from 0.3 to $20 \mu \mathrm{m}$ diameter using backscatter and a Droplet Measurement Technologies-modified Particle Measurement Systems Forward Scattering Spectrometer Probe (FSSP-100) with a rotating base to maintain alignment with the prevailing wind was used to retrieve distributions from 0.5 to $47 \mu \mathrm{m}$ in 16 channels.

A pair of four-stage Berner type aerosol impactors ${ }^{45}$ were located at the top of the west-face of the tower. At a flow rate of $82 \mathrm{~L} \mathrm{~min}^{-1}$, the aerosol size cut-offs for each stage were $0.2 \mu \mathrm{m}$ (Backup filter), $0.2-0.5 \mu \mathrm{m}$ (stage 1); 0.5-1.5 $\mu \mathrm{m}$ (stage 2); 1.5-5.5 $\mu \mathrm{m}$ (stage 3); 5.5-10 $\mu \mathrm{m}$ (stage 4). Stages 1 to 4 were equipped with Tedlar substrates extensively pre-washed with milliQ water. The same cleaning procedure was adopted for the Teflon back-up filters. Based upon forecast backtrajectories, prevailing synoptic conditions and local wind speed and direction, it was attempted to ensure that each series of samples was collected in a single air mass classification. This frequently entailed rotation of impactor cartridges and discontinuous sampling. Six sets of samples of varying duration (based on loading predicted by appropriate integration of size bins from the Grimm OPC) were collected throughout the campaign. The samples were refrigerated and sent for analysis. Each sample was extracted in deionised water in an ultrasonic bath and divided for a variety of determinations: ion chromatography, total organic carbon (TOC) analysis and organic speciation by ion-exchange chromatography. This final analysis using a HPLC system (Hitachi L-7100) equipped with a DEAE-TSK gel column $(7.5 \mathrm{~mm}$ id and $7.5 \mathrm{~cm}$ long) and a UV detector provides fractionation of the WSOC into three groupings: neutral compounds (NC), mono- and di-acids (MDA) and polyacidic compounds (PA).

In addition to the Berner impactors, two Graseby Andersen Hi-Vol six-stage impactors with glass, or a mixture of quartz and glass, filters were deployed on the top of the tower for aerosol analyses requiring a greater mass. At a flow rate of $1.12 \mathrm{~m}^{3} \mathrm{~min}^{-1}$, the size cut-offs for each stage were $4.49 \mu \mathrm{m}$ (stage 1); $1.87 \mu \mathrm{m}$ (stage 2); $0.91 \mu \mathrm{m}$ (stage 3); $0.6 \mu \mathrm{m}$ (stage 4); $0.32 \mu \mathrm{m}$ (stage 5); 0.18 $\mu \mathrm{m}$ (stage 6). Samples from the quartz filters were extracted similarly and, using ion-exchange chromatography and proton nuclear magnetic resonance $\left({ }^{1} \mathrm{H} N \mathrm{NR}\right)$, a functional group analysis of the groupings of WSOC was performed. The glass filters were extracted in deionised water, separated by size-exclusion chromatography with a molecular cut-off of $5000 \mathrm{Da}$ and analysed for nitrogen, total, organic and inorganic carbon and protein; the analytical techniques have been described elsewhere.

\section{Aerosol composition distributions during the first TORCH experiment}

Impactor sampling has been combined with the online AMS analysis in four field projects to-date. There is no reason to expect that the non-refractory AMS organic mass loading should exactly correspond to the organic loading from the impactor, operationally-defined by the analysis as WSOC. Topping et al. ${ }^{46}$ and Decesari et $a l .{ }^{47}$ present a characterisation of aerosol composition from the ACE Asia field project on Jeju Island in the South China Sea off the coast of South Korea. It was shown in Topping et al $^{46}$ that the WSOC mass loading from the first two impactor stages (corresponding to particles between $200 \mathrm{~nm}$ and $1 \mu \mathrm{m}$ in diameter) agreed very well with the total AMS organic mass loading time series. Fig. 2 shows a comparison between the non-refractory submicrometre aerosol particulate loading measured by the AMS and the Berner impactor WSOC loading during the first TORCH experiment. The smallest two stages of the impactor (the darkest horizontal bars and those with the highest loadings), collecting particles between $200 \mathrm{~nm}$ and $1 \mu \mathrm{m}$ in diameter, roughly correspond to the fraction of the aerosol particles passing through the AMS aerodynamic lens inlet with unity efficiency.

Summing the WSOC loadings on these two impactor stages, it can be seen that there is good general agreement between the offline and online analyses. It can also be seen that the fourth, fifth and sixth impactor samples were discontinuous to allow sampling during similar conditions for each discrete sample. It was found that the loading on the 6th sample was too low for organic analysis. The top panels in Fig. 3 shows the total fine fraction major ion plus WSOC contributions to mass 


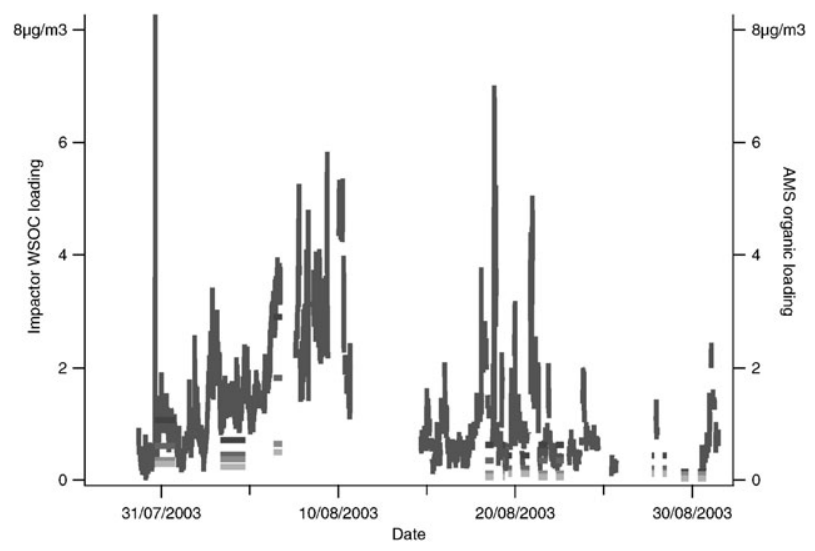

Fig. 2 Total sub-micrometre particle non-refractory organic mass loading measured by the AMS during TORCH 1 plotted with WSOC loadings from each impactor stage. The loadings from the stage with the lowest size cut are the darkest horizontal bars, the masses of larger particles represented by progressively lighter bars (see text for size cuts). The sum of the loading from the two smallest stages should correspond roughly to the mass of particles entering the AMS. It can be seen that there is generally good agreement between the impactor and AMS measurements.
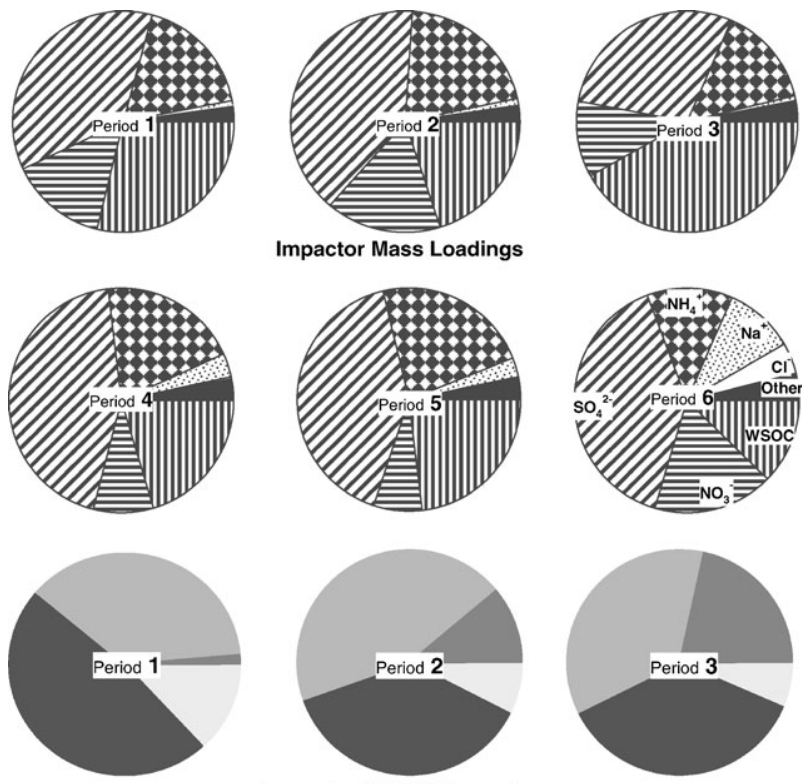

Impactor WSOC Groupings
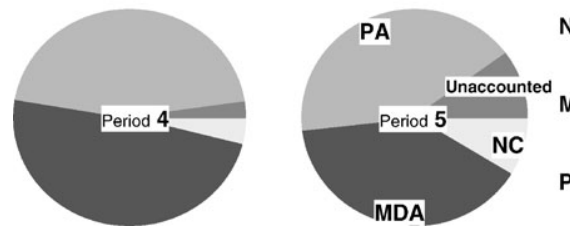
NC Neutral Compounds
MDA Mono- \& Diacidic Compounds
PA Polyacidic Compounds

Fig. 3 Top panels: Major ion and WSOC contributions to mass loading from the two Berner impactor stages with the finest size cuts. Inorganic compounds contribute between around half and three quarters of the mass in all samples and there is a significant WSOC contribution to the total loading. The bottom panels show broad group contributions to the total WSOC mass from the same periods. Most of the WSOC mass is contributed by acidic compounds with a significant proportion of polyfunctional acidic compounds. 
Table 1 Relative molar contributions to the representative model organic compounds based on HPLC and ${ }^{1}$ H NMR analyses

\begin{tabular}{|c|c|c|c|c|}
\hline & TORCH & $\begin{array}{l}\text { Contribution } \\
(\mathrm{mol} \%)\end{array}$ & Po valley & $\begin{array}{l}\text { Contribution } \\
(\mathrm{mol} \%)\end{array}$ \\
\hline \multirow[t]{3}{*}{$\mathrm{NC}$} & D-Galactal & 9 & Levoglucosan & 11.9 \\
\hline & Andrographolide & 4 & Pinonaldehyde & 20.4 \\
\hline & & & Catechol & 3.9 \\
\hline \multirow[t]{6}{*}{ MDA } & Acetic acid & 7 & Nonanedioic acid & 16.0 \\
\hline & Oxalic acid & 9 & 3-Hydroxybutanoic acid & 31.2 \\
\hline & Methanesulfonic acid & 7 & 3-Hydroxybenzoic acid & 4.7 \\
\hline & 2-Methyl-7-oxononanoic acid & 28 & & \\
\hline & 4-Oxoheptanedioic acid & 16 & & \\
\hline & Aromatic mid MW acid ${ }^{a}$ & 5 & & \\
\hline PA & Suwannee River Fulvic Acid & 15 & Suwannee River Fulvic Acid & 11.9 \\
\hline
\end{tabular}

loading from analyses of aerosol sampled on the first two stages of the Berner impactors. At these sizes it can be seen that, with the exception of the 6th period with low total loading, inorganic compounds contribute between around half and three quarters of particulate mass in all bulk samples and that there is a significant contribution of organic compounds to the total loading. The most heavily loaded sample (period 3 ) has the greatest contribution from organic material. The bottom panels show relative group contributions to the total WSOC mass from the same periods. In all samples, the bulk of the WSOC mass is contributed by acidic compounds with a significant proportion of polyfunctional acidic compounds.

Attribution of model compounds to three operational groupings of WSOC (NC, MDA and PA) has been used to provide a representation of fine aerosol organic material generally capable of reproducing the ${ }^{1} \mathrm{H}$ NMR measured aerosol functionality. The relative molar loadings of model compounds satisfying the organic functionality are shown in Table 1. It should be noted that it is not suggested that these are the compounds actually present in atmospheric particulates, but that their choice closely balances the mass of the functional groups identified in the analyses. Due to the labour intensive nature of the impactor analyses and the consequent insufficiency of highly timeresolved data it is not possible to state that, at any one location, the representative compound combinations are invariant. For the rest of the current analysis we will assume this to be the case; however there are known differences between these combinations from location to location, presumably dependent on the prevailing source contributions and histories of the air masses from each source. For comparison, Table 1 also shows the model compounds satisfying the ${ }^{1} \mathrm{H}$ NMR functional analysis from a project conducted in the Po valley in Italy. ${ }^{6}$

\section{Detailed thermodynamic model use of functional representation of organics to predict hygroscopicity:}

There have been a number of recent attempts to explicitly treat the thermodynamics of multicomponent inorganic/organic aerosols. ${ }^{48,49}$ The Aerosol Diameter Dependent Equilibrium Model $(\mathrm{ADDEM})^{37,38}$ was recently developed to describe the water content of a particle based the contribution from all inorganic and organic components. The model uses a constrained minimisation of the total Gibbs free energy of all solute, solvent and solid components in a mixed aerosol particle to calculate its equilibrium state. The Gibbs free energy is calculated as the summation of the chemical potential of each component; each chemical potential being expressed in terms of the component activity. The inorganic activities are calculated using the Pitzer-Simonsen-Clegg mole fraction based ionic interaction model, ${ }^{50,51}$ whilst the organic activities are calculated using UNIFAC $^{52}$ with modified polar group contribution parameters. ${ }^{53}$ The formation of solids is suppressed when organic components are considered due to the lack of available fundamental 
Table 2 The variation in the primary and background contribution to measured particulate organic loading is illustated by correlating the average fragmentation pattern with the representative spectra for lubricating oil and fulvic acid. The table is ordered from the most remote sampling location through to the closest to source showing that most of the variance in the pattern in the remote locations can be explained by the contribution from the fulvic acid spectrum and that from urban locations by the lubricating oil spectrum

\begin{tabular}{lll}
\hline & \multicolumn{2}{l}{ Pearson's $r$ value } \\
\cline { 2 - 3 } Location & Fulvic acid & Lubricating oil \\
\hline Jeju Island, remote marine & 0.96 & 0.26 \\
Jungfraujoch, high alpine & 0.95 & 0.31 \\
Langley, rural & 0.87 & 0.47 \\
Vancouver, oxidised urban & 0.87 & 0.50 \\
Vancouver, traffic urban & 0.50 & 0.87 \\
Manchester, traffic urban & 0.46 & 0.90 \\
New York, diesel exhaust & 0.14 & 0.97 \\
\hline
\end{tabular}

data for appropriate solid formation. Likewise, the lack of organic-inorganic solute interaction data would limit the applicability of the model to non-atmospheric mixtures if their inclusion was attempted (organic-inorganic interactions may be "solvent" or "anti-solvent" in tendency and estimation of the direction and magnitude of the tendency is unreliable). Thus the water contributions of the organic and inorganic fraction are additive, preserving the essence of the ZdanowskiStokes-Robinson relationship. ${ }^{54}$ Nevertheless, the model can reproduce the available laboratory data for mixed systems accurately to low $\mathrm{RH}^{37}$ To capture the varying behaviour with curvature, and hence particle size, and realistically represent the Kelvin effect, the whole minimisation is embedded within an iterative scheme evaluating multicomponent density and surface tension. The composition from the coarsely resolved impactor composition measured during TORCH with its derived model compounds (detailed in Table 1) was mapped onto the fine size resolution of the AMS aerosol time-of-flight mass distribution averaged over the same time period and used to initialise ADDEM, making it possible to predict the $\mathrm{GF}_{\mathrm{D}}$ of the particles as a function of size. The detail of this procedure and model application to predict $\mathrm{GF}_{\mathrm{D}}$ as a function of humidity to reproduce HTDMA humidograms is the subject of another publication, but an example of the prediction is shown in Fig. 4. It can be seen that for the particular impactor period, the HTDMA measured $\mathrm{GF}_{\mathrm{D}}$ to $90 \% \mathrm{RH}$ is reproduced within the measurement uncertainty using the measured composition for all but the largest $360 \mathrm{~nm}$ dry diameter particles (for these larger particles, it is possible that the equilibration timescale is longer than the residence time in the HTDMA humidifier). This initially appears encouraging. However, further investigation of the contribution of the organic material to the hygroscopicity reveals an interesting result. Fig. 5 shows the prediction of the wet to dry mass ratio (related to the cube of the $G_{\mathrm{D}}$ and the multicomponent mixture density) for four organic bulk solutions in equilibrium with varying RH (equal to the water activity for large particles where the contribution from the Kelvin effect is negligible). The first three cases are (i) the model compounds from the Po Valley in their relative mass fractions, (ii) similarly the TORCH model compounds and (iii) Suwannee River Fulvic Acid, a compound frequently used as a proxy for HULIS in atmospheric particulates and a compound closely representing the functionality found in the PA fraction in both the Po Valley and TORCH analyses. At $90 \% \mathrm{RH}$ the predicted mass ratio corresponds to $\mathrm{GF}_{\mathrm{D}}$ values of 1.1081, 1.1098 and 1.08, respectively. For particles smaller than $100 \mathrm{~nm}$ or so where the Kelvin term must be accounted for, this will be further reduced. Referring back to Fig. 4, it can be seen that the growth factor for the particles greater than $137 \mathrm{~nm}$, the $\mathrm{GF}_{\mathrm{D}}$ is greater than 1.4. For an organic mass contribution of around $1 / 3$ (and a significantly lower mole fraction), the contribution from even the most oxidised organic fraction (as represented by the model compounds for the WSOC sampled in the $200 \mathrm{~nm}$ plus impactor stages) to the hygroscopicity will be negligible. Further, it is shown below that even the low hygroscopicity $(\mathrm{LH})$ mode has a $\mathrm{GF}_{\mathrm{D}}$ greater than that which even an oxidised organic component can impart (and it might reasonably be expected that organic material near to source is largely insoluble with a $\mathrm{GF}_{\mathrm{D}}$ approximately equal to unity). The changes resulting in the more hygroscopic ( $\mathrm{MH}$ ) mode must 

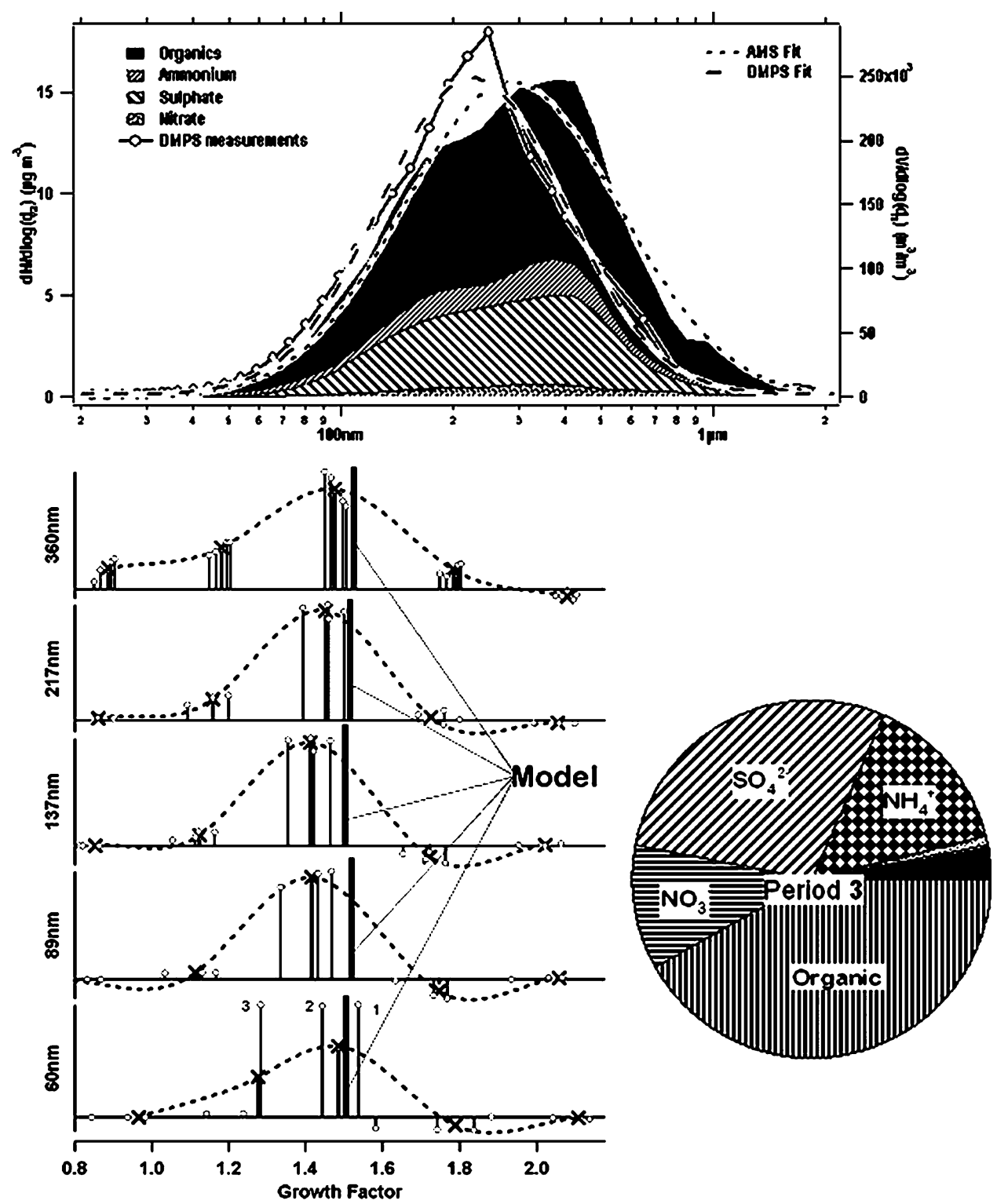

Fig. 4 Bottom left, $\mathrm{GF}_{\mathrm{D}}$ to $90 \% \mathrm{RH}$ predicted by the ADDEM model compared with that measured by the HTDMA during TORCH 1 impactor period 3. The other panels show input initialisation composition for TORCH impactor period 3. The absolute loadings from the impactor (bottom pie chart) were used to normalise the AMS loadings across the distribution, top panel (the directly-measured absolute AMS loadings are not yet available).

be due to changing inorganic composition. This indicates that, so far as water affinity in the sub-saturated regime is concerned, an atmospherically realistic amount of oxidised organic material will only make a minor contribution to water content.

Two further considerations need to be made interpreting this analysis. The first is that there is indication from emerging analyses of the glass $\mathrm{Hi}-\mathrm{Vol}$ filters that there may be a significant fraction of WSOC (of the order of $30 \%$ in many cases, increasing with increasing particle size) contributed by macromolecular nitrogen-containing compounds, probably proteins, of greater than $5000 \mathrm{Da}$. 


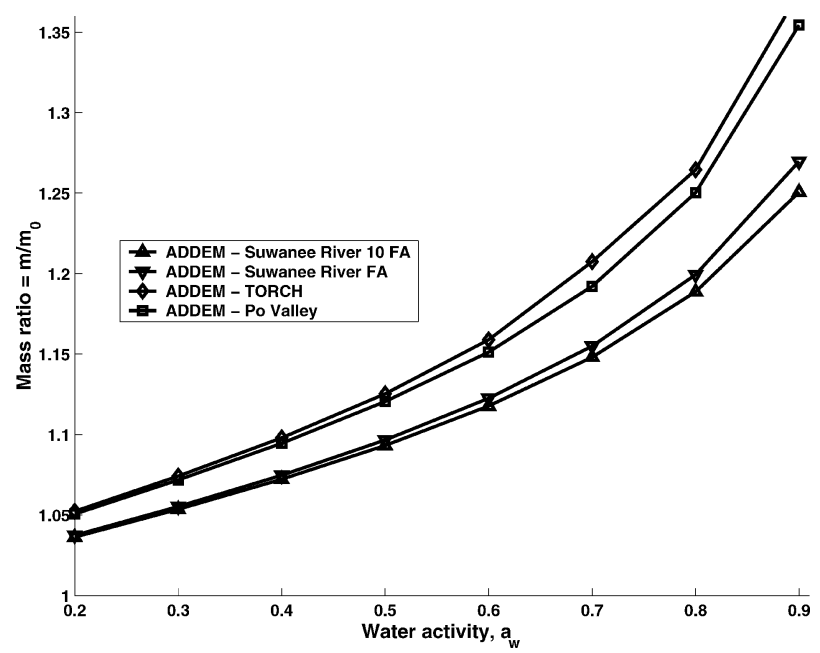

Fig. 5 Wet to dry mass ratio predictions (related to the cube of the diameter growth factor, $\mathrm{GF}_{\mathrm{D}}{ }^{3}$ ) for four aqueous solutions of organic compounds (i) the model compounds representing the TORCH ${ }^{1} \mathrm{H}$ NMR functional group analysis, (ii) the corresponding Po valley compounds. It can be seen that the model representations of the organic aerosol component from each location behave almost identically and grow very little up to ver high values of RH, (iii) Suwannee River Fulvic Acid, the model compound closely representing the PA fraction of WSOC and (iv) a compound comprising ten times the number of functional groups of fulvic acid. The predicted growth of an equal mass of a macromolecular highly oxygenated compound containing the functionality of ten times the fulvic acid molecule and corresponding mass is almost identical (but slightly lower) than fulvic acid, and lower than that of ambient aerosol particles.

Whilst no explicit calculation of the water affinity of these compounds has been made, the number of molecules per unit mass will be significantly lower than the largest model compounds currently considered and hence will be associated with even less water (i.e. even lower $\mathrm{GF}_{\mathrm{D}}$ ). In attributing the model compounds to the ${ }^{1} \mathrm{H}$ NMR analysed impactor samples, no account is taken of information about molecular size. To explore the potential effect of the presence of macromolecules, the fourth curve in Fig. 5 shows the predicted mass ratio variation with relative humidity of a hypothetical macromolecular organic compound comprising the functional groups of ten fulvic acid molecules. For the same mass (i.e. ten times fewer molecules) it can be seen that there is a marginal decrease in the water activity. Hence the calculation of hygroscopicity when the organic component is macromolecular is even less dependent on organic compounds present, only on the relative abundance of organic and inorganic components in the particle. The second consideration is that the volatility SMPS indicated that there was only a small contribution to the aerosol distribution from refractory material at any size. This indicates that the AMS loading will be reasonably accurate, and that elemental carbon (EC) mass contribution will be low throughout the distribution.

It should be noted that only a single $\mathrm{GF}_{\mathrm{D}}$ value can be predicted using the assumption of full internal mixing in contrast to the observed finite breadth of the HTDMA-measured GF $_{D}$ distribution. An inversion of the composition distribution using HTDMA-derived mixing state would allow prediction of a $\mathrm{GF}_{\mathrm{D}}$ distribution for comparison with that measured. This is the subject of ongoing investigation.

\section{AMS characterisation of organic particulate material at several mid-latitude northern hemisphere locations}

Detailed composition analyses using the AMS have been performed at a variety of locations. The data used and summarised here were collected in urban locations in Manchester (summer and winter) and Edinburgh in the UK, in Vancouver and rural (Langley) and semi-rural (Sumas) locations in Canada, on the Jungfraujoch, a high alpine site in central Europe and on a remote marine site on Jeju Island, South Korea. No detailed analysis of the individual field studies will be 
presented here (the data have been published for the two UK cities, ${ }^{41}$ for the Korean experiment ${ }^{46}$ and the Canadian study ${ }^{44,55}$ ). Fig. 6 shows the mass size distributions of the sulfate, nitrate, ammonium and organic fractions of the aerosol particles averaged over the whole sampling period at each location. A significant accumulation mode, principally composed of sulfate, nitrate, ammonium and organic material with vacuum aerodynamic diameters between $300-800 \mathrm{~nm}$, peaking around 400-500 nm, was observed at all sites. A significant mass mode composed of organic material with very small concentrations of inorganic species at a diameter of about 100-200 nm was constantly observed at all urban sites and when fresh or urban air masses affected the other sites. ${ }^{55}$ This is consistent with previous observations made in other urban sites in the US. ${ }^{42,43}$ This smaller-sized organic mode is characteristic of urban sites and fresh emissions. At non-urban sites, the measurements were made away from local sources, the small mode became less significant and the distribution was dominated by the accumulation mode. Observed mass size distributions at all urban sites (panels A-D, Fig. 6) reveal consistently similar bimodal organic and monomodal inorganic distributions (though there is an observed difference in the lower size cut-off of the measured organic distributions due to the difference in the particle transmission efficiency of the aerodynamic lens that was upgraded before the Pacific 2001 experiment ${ }^{56}$ ). The temporal variations of the accumulation mode component size distributions contributing to these averages at all locations suggest that they are internally mixed and are indicative of a regional background mode. $^{41,55}$ Further evidence for internal mixing is provided by the similar modal diameters and

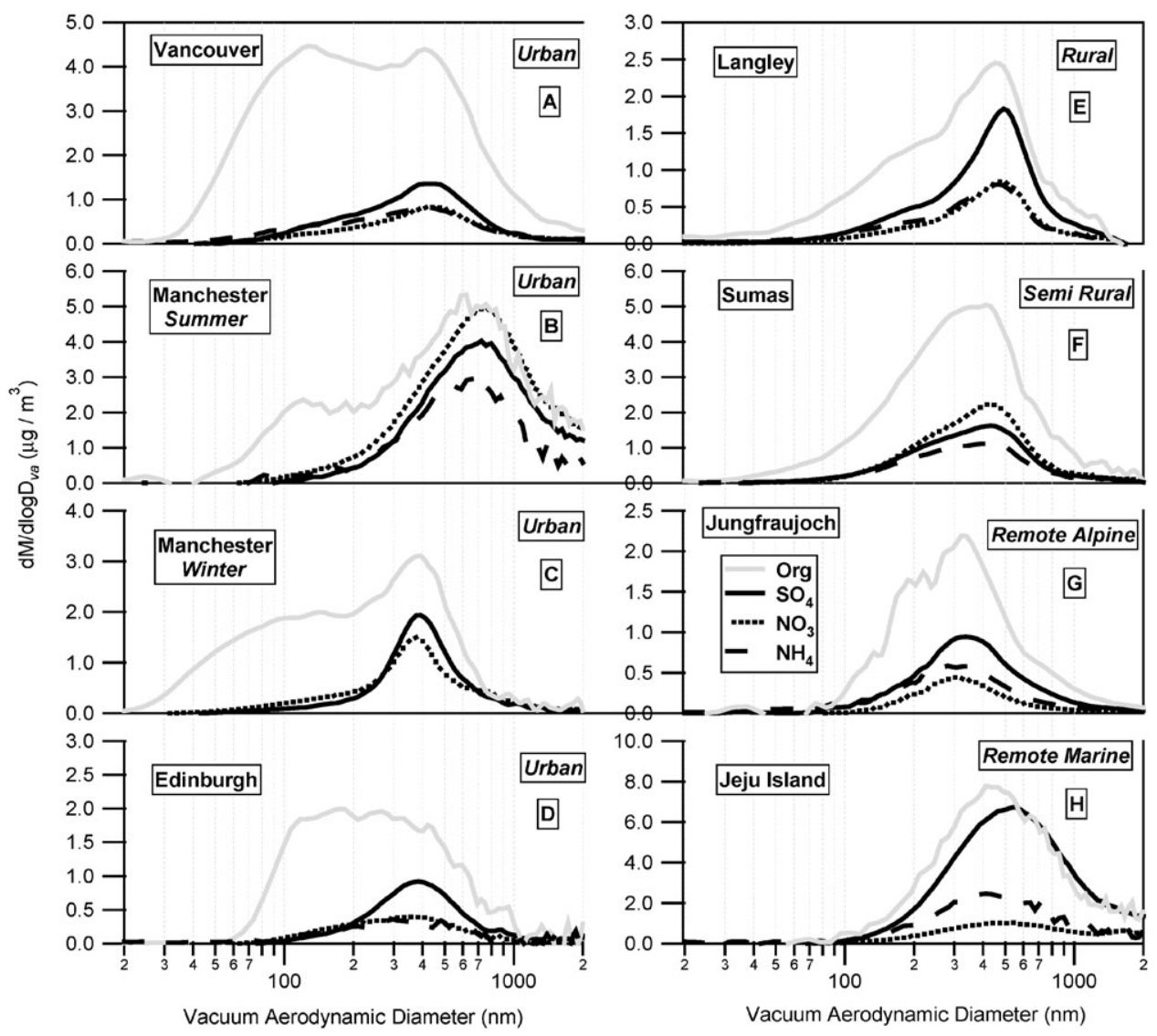

Fig. 6 Mass size distributions of the organic, sulfate, nitrate and ammonium fractions of the aerosol particles measured by the AMS at various urban, rural and remote locations. Data are averaged over the entire sampling period at each of the locations. Note the varying ranges of the $y$-axes. The left hand panels from polluted locations show a smaller, externally-mixed organic mode which is absent in more remote locations. 
mode shapes of the component mass distributions; as the vacuum aerodynamic diameter is density dependent these would be expected to be different if the particles were externally mixed.

The results reveal that the organic fraction is the most significant contributor to the total mass measured by the AMS at all of the sampling locations, accounting for $38-70 \%$ of the total mass. Organic material has been found to account for $70 \%$ of the total mass measured at the Slocan Park urban site in Vancouver, which represent an emissions-dominated regime. However, organics accounted for $53 \%$ of the total mass measured at the Jungfraujoch high alpine research station, which is a remote site away from local sources. These results illustrate the ubiquity of organic material in Northern Hemisphere mid-latitudes, whilst highlighting a difference in behaviour as a function of the distance from source regions that warrants further investigation.

The small mode organic mass loading during the Vancouver urban study was strongly correlated with gas phase $\mathrm{CO}$, benzene, 1,3-butadiene and toluene: ${ }^{44}$ all good markers for transport-related emissions, with Pearson's $r$ values of $0.76,0.79,0.71$ and 0.69 , respectively. An even stronger correlation between the small mode organic loading and $\mathrm{NO}_{x}(r=0.86)$ was found for Manchester. The characteristic fragmentation of organic compounds in the AMS was used to investigate organic aerosol behaviour during the Canadian studies. It was been found that the fragments at $m / z=44$, 43 and 57 may be used to explore the degree of oxygenation of the contributions to the organic material. The $m / z 44\left(\mathrm{CO}_{2}{ }^{+}\right)$fragment has been found in the laboratory to be reproducibly produced by the thermal decarboxylation of oxo-, di- and poly-carboxylic acids and humic-like substances on the vapouriser, for which it is a main ion fragment, other compounds show little or no ion signals at this mass peak. $m / z 43$ is a characteristic fragment of both saturated hydrocarbon compounds $\left(\mathrm{C}_{3} \mathrm{H}_{7}{ }^{+}\right)$and oxidised organic compounds such as aldehydes and ketones $\left(\mathrm{CH}_{3} \mathrm{CO}^{+}\right.$or its isomers) and $m / z 57$ is a typical fragment of saturated hydrocarbon compounds $\left(\mathrm{C}_{4} \mathrm{H}_{9}{ }^{+}\right)$and generally receives a negligible contribution from atmospheric oxidised organic compounds. A correlation of the mass concentration of $m / z 57$ with the concentration of the $\mathrm{CO}$ at the urban site in Vancouver had a Pearson's $r$ value of 0.74 , while a similar correlation using $m / z 44$ at the same location had a Pearson's $r$ value of 0.42 . Similar correlations have been performed with the Manchester winter data using $\mathrm{NO}_{x}$ as the primary marker and resulted in Pearson's $r$ values of 0.85 and 0.24 for $m / z 57$ and $m / z$ 44, respectively. These correlations support the selection of $m / z 57$ as a marker for freshly emitted organic combustion aerosol in the AMS data and may rule out any significant contribution of primary emissions to $m / z$ 44. Fig. 7 shows the mass size distributions of these three key organic mass fragments averaged over the whole sampling period at each of the sampling locations. The $m / z 44$ shows a pronounced monomodal distribution, with a modal diameter of about $400-450 \mathrm{~nm}$ in all but Manchester summer data, where a larger modal diameter of about $700 \mathrm{~nm}$ has been observed. This is strong evidence for internal mixing between oxygenated organics and sulfate in the Manchester summer data, as the latter also shows a similar increase in the modal diameter at this location. The distribution for $m / z 44$ is not available for the Edinburgh data, because this mass fragment was not scanned in the TOF mode. The domination of a monomodal distribution of $m / z 44$ in the urban sites implies that there is little contribution from highly oxygenated organic compounds in the small organic mode. In addition, the relative magnitudes of $m / z 44$ to the other two fragments indicate the presence of more oxidised organic compounds in the Manchester summer and Vancouver data relative to that of Manchester winter. In the rural locations dominance of mass fragments 44 and 43 in the accumulation mode and the lack of significant contributions from mass fragments 57 and 43 in the small mode (compared to the urban sites in the left hand panels) suggest that organic particulate at these sites has a large contribution from oxygenated compounds, and that they are more significant than primary unoxidised organic material at these locations during the sampling periods. Each of the mass fragments seems to have similar size distributions in all non-urban locations. However the $m / z 44$ appears to be more pronounced relative to $m / z 43$ at the Jungfraujoch and Jeju Island remote sites, possibly suggesting more atmospheric processing at those locations relative to Langley and Sumas sites. At the urban locations, the mass fragments at $\mathrm{m} / \mathrm{z} 43$ and 57 show bimodal mass size distributions similar to that observed for the total organic aerosol fraction shown in Fig. 6.

The mass spectral signatures may be used to provide more information on the organic composition. Panel $\mathrm{C}$ in the left column of Fig. 8 shows a mass spectrum of New York diesel bus exhaust aerosol. ${ }^{57}$ This spectrum was compared to laboratory generated diesel fuel (left panel A) and lubricating oil (left panel B) spectra leading to the conclusion that under most operating 


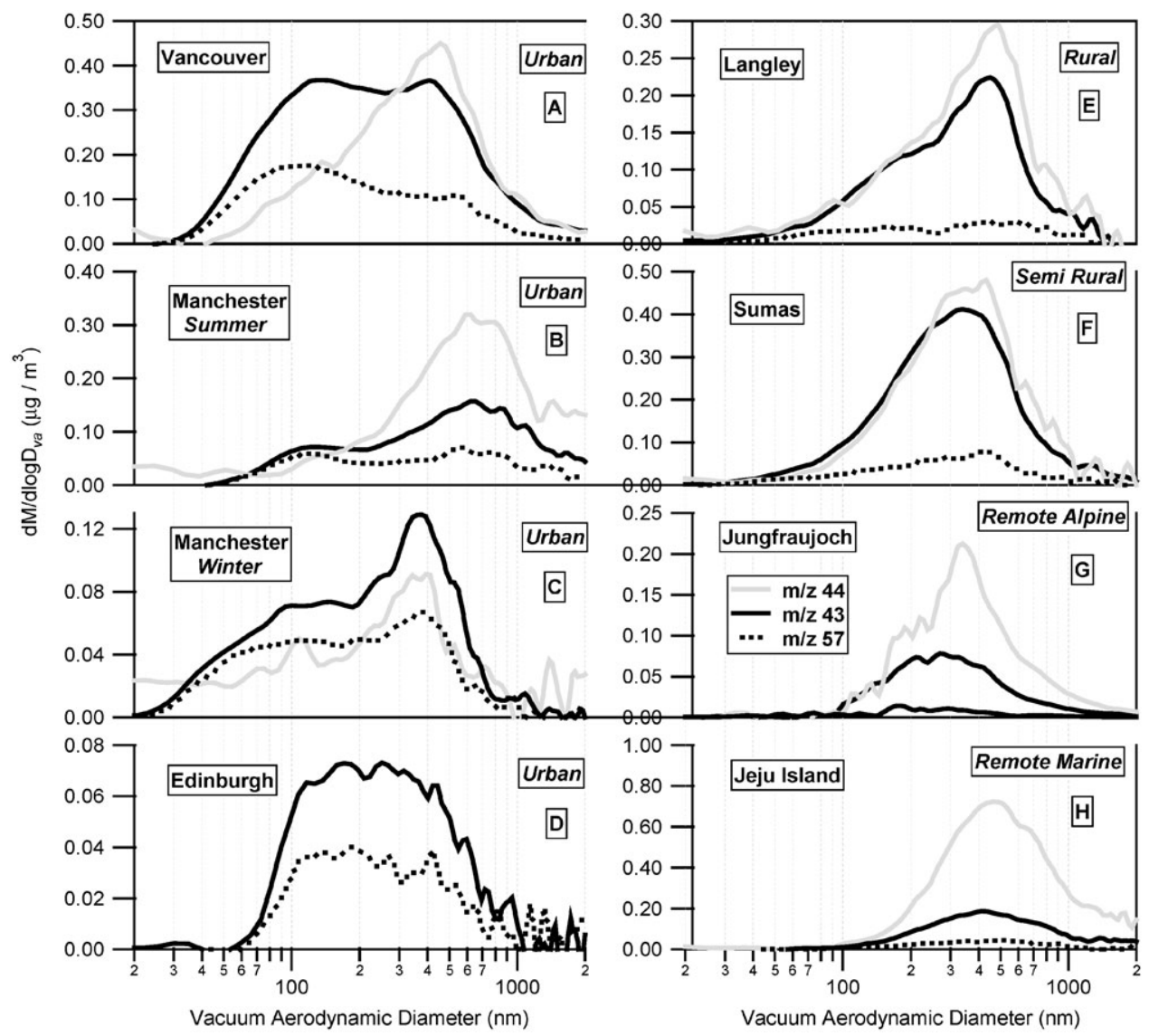

Fig. 7 The mass size distributions of three key organic mass fragments averaged over the whole sampling period at each of the sampling locations. $m / z=57$ is a marker for freshly-emitted combustion-derived organic compounds and is enhanced in smaller sized particles in ambient distributions from polluted locations (left panels). This contrasts to $m / z=44$ which is derived solely from decarboxylation of dicarboxylic acids and organic polyacids and is enhanced. It is preferentially found in the accumulation mode and is enhanced in the background distributions in more remote locations (right panels). $m / z=43$ is derived from both oxygenated and hydrocarbon-like compounds.

conditions the organic carbon fraction of in-use diesel vehicle exhaust aerosol is dominated by the recondensed vapour from the evaporated (and/or partially combusted) engine lubricating oil. All spectra were dominated by the ion series $\mathrm{C}_{n} \mathrm{H}_{2 n+1}{ }^{+}(\mathrm{m} / z 29,43,57,71,85 \ldots)$, which is typical of saturated normal and branched alkanes. Other important ion series were also observed including $\mathrm{C}_{n} \mathrm{H}_{2 n-1}{ }^{+}(m / z 27,41,55,69,83 \ldots)$ typical of alkenes, $\mathrm{C}_{n} \mathrm{H}_{2 n-3}{ }^{+}(m / z$ 67, 79, 81, 95, 107, $109 \ldots)$ typical of cycloalkanes and $\mathrm{C}_{6} \mathrm{H}_{5} \mathrm{C}_{n} \mathrm{H}_{2 n}{ }^{+}(\mathrm{m} / z 77,91,105,119 \ldots)$ typical of aromatic hydrocarbons. ${ }^{58}$ Left panel D shows a mass spectrum of the organic fraction measured at the Vancouver urban site during periods dominated by traffic emissions. A similar mass spectrum is shown in panel E for the Manchester winter sampling period (the spectra are averaged over all periods where $\mathrm{CO}$ concentrations were higher than the local averages (403 ppbv in Vancouver and 289 ppbv in Manchester winter)). A comparison of the spectra in panels D and E with that in panel $\mathrm{C}$ suggests significant similarity in the composition of traffic-dominated ambient organic particulate in Manchester and Vancouver and that of diesel exhaust organic in New York City. The similarity of the ambient spectra and the laboratory generated lubricating oil spectrum indicates that recondensed vapour from engine lubricating oil dominated the organic fraction in Manchester and Vancouver during the sampling periods. A closer inspection of the spectra in the left panels 

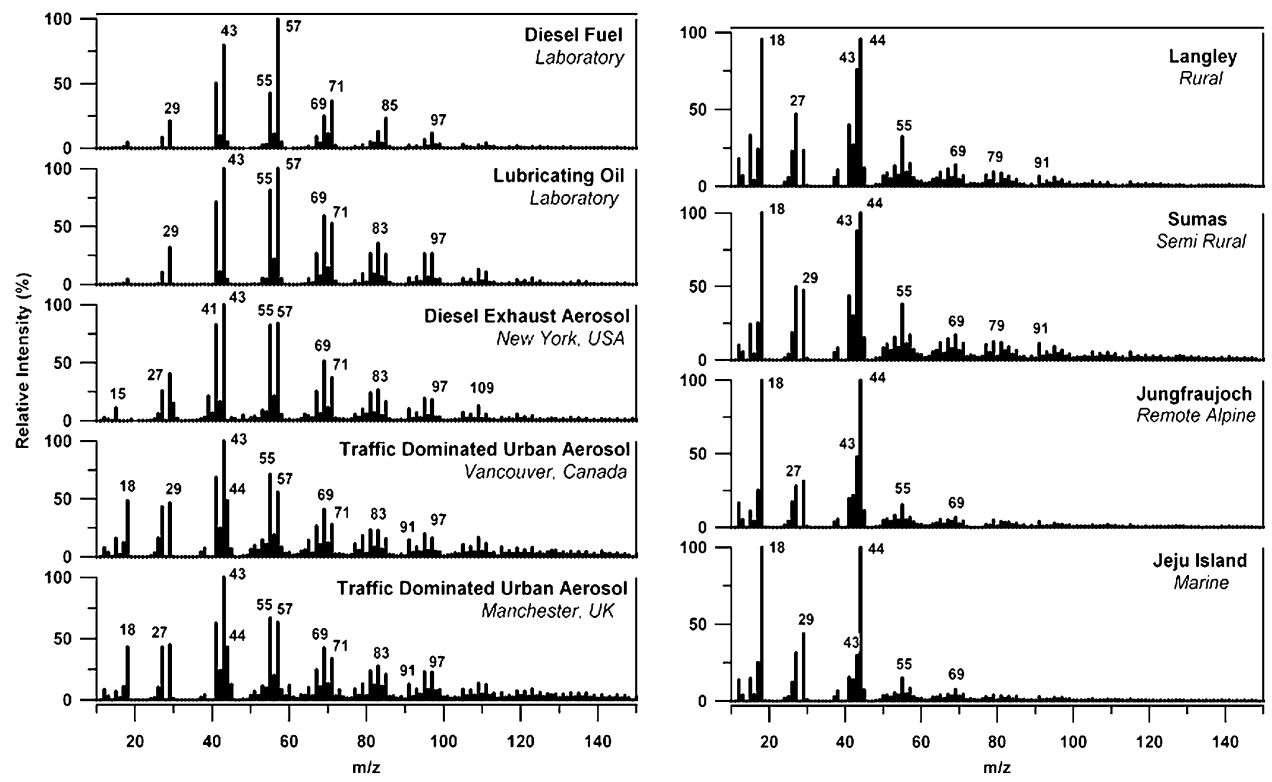

Fig. 8 Averaged AMS mass spectra from a variety of locations compared with spectra measured from nebulised lubricating oil and diesel fuel. The similarity of the characteristic fragmentation pattern of urban spectra to that of lubricating oil and diesel fuel is apparent, as is the difference to that in remote locations. This is explored further in the text and Table 2.

shows that the ambient spectra have an extra fragment at $m / z$ 44, a more enhanced $m / z 43$ relative to its adjacent fragments and a more abundant $m / z 55$ relative to $m / z 57$. Oxygenated organic compounds from the separate accumulation mode are likely to contribute to each of these differences (and partial combustion of the lubricating oil vapour may contribute to the variation in $m / z 55$ to 57 ratio).

The right hand panels in Fig. 8 show mass spectra of the organic aerosol fraction averaged over the sampling duration at each of non-urban sites. The mass spectral signatures are similar at all sites and the most significant contributions to these spectra arise from mass fragments characteristic of oxygenated organic compounds such as $m / z 44$ in addition to mass fragments 43 and 55 . The rural and semi rural spectra (right panels A and B, receptively) show some contribution from fragments typical of aromatic and cyclic compounds such as 67, 79, 91, 95 and 105. However, the spectra in panels $\mathrm{C}$ and $\mathrm{D}$ show that these mass fragments are much less observed at the Jungfraujoch and Jeju Island remote sites, supporting an argument that organic particulates may have been exposed to more processing at those two locations. It may be expected that, since an air parcel represents the integrated history of all its emissions and chemical transformations, a representation of the organic aerosol component by a generic species meant to capture the behaviour of oxygenated particulate organics in a remote environment will not capture the behaviour of air parcels significantly influenced by recent emissions. However, the explanation of almost all the variance in background organic particulates by a single, $m / z=44$ dominated, fraction allows a simple intuitive separation of organic aerosol material. Following the conclusion that the $m / z=57$ dominated organic fraction is derived from source driven primary emission, it is possible to state that condensed organics may be represented by two components within the lifetimes of particulate sampled during all these northern hemisphere mid-latitude field studies. These two components are the, generally unoxidised, HOA (hydrocarbon-like) and OOA (oxygenated organic aerosol). ${ }^{59}$ It would be useful to identify a generic representation for the oxygenated organic material, using a single compound or known mixture capturing the features of the background remote organic in the same way that lubricating oil appears to capture the urban organic aerosol components. It may be expected that such a representation would have a mass fragmentation pattern similar to that at the more processed 
locations. Therefore we now attempt to derive a representative EI mass fragmentation pattern for the oxygenated fraction.

\section{Attribution of representative AMS mass fragmentation pattern to the oxygenated organic fraction}

To conduct a preliminary investigation of the AMS response to model compounds retrieved from the impactor analysis (and based on the demonstrated importance of compounds with properties similar to HULIS), an AMS spectrum of the standard fulvic acid reference (Suwannee River Fulvic Acid) was obtained using particles generated in the laboratory. The AMS mass spectrum of fulvic acid (panel A, Fig. 9) is dominated by $m / z 44\left(\mathrm{CO}_{2}{ }^{+}\right)$identified as the AMS signature of highly oxidised compounds such as hydroxy- and di-carboxylic acids. There is also predicted to be significant contributions from $m / z 18$ and $m / z 28$ due to the associated $\mathrm{H}_{2} \mathrm{O}$ and $\mathrm{CO}$ formed in the decarboxylation process and subsequently ionised. The contribution of mass fragment 18 to the fulvic acid mass spectrum has been calculated by subtracting the air beam contribution to $\mathrm{m} / \mathrm{z} 18$ assuming the particles are dry. This is not possible to retrieve from ambient data due to interferences from ammonium, sulfate and gas phase and particulate water, and as a result $m / z 18$ is set to equal $m / z 44$ as an estimation of the minimum contribution of $m / z 18$ to the organic mass. Fig. 9 compares the fulvic acid mass spectrum signature with ambient organic mass spectra obtained from the urban, rural and remote locations described here. The comparison reveals that the mass spectral signatures of organic particulate in the remote, rural and oxidised urban sites are highly similar to that of humic-like compounds and were all dominated by $m / z$ 44. On the other hand, the traffic dominated organic spectrum measured in Vancouver showed a different signature to that of fulvic acid, where $m / z 43$ and other aliphatic fragments were far more dominant than $m / z 44$.

We now have a strong indication that, at least for continentally influenced northern mid-latitude locations where these data were obtained, it may be appropriate to use just two components to

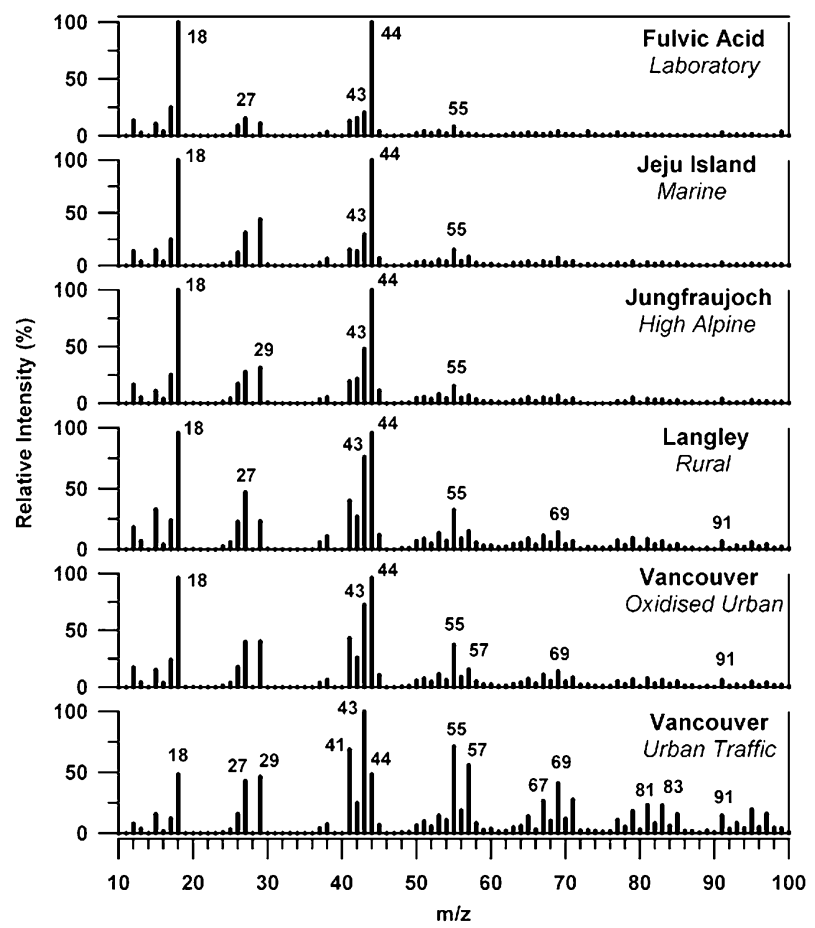

Fig. 9 Reference mass spectrum from Suwannee River Fulvic Acid and averaged atmospheric mass spectra from a variety of locations. The representative HULIS has a fragmentation pattern close to that in background remote locations, the similarity reducing with increased fresh pollution input (i.e. as the sampling location moves closer to source). This is explored further in the text and Table 2. 
represent the organic component of atmospheric aerosols; the primary organic contribution playing a significant role near source, but reducing in importance moving towards the background atmosphere. The similarity among the ambient spectra in Fig. 9 and the fulvic acid spectrum was quantified by scattering the values of each of the averaged atmospheric mass spectra against those of fulvic acid and lubricating oil, respectively, calculating the Pearson's $r$ values summarised in Table 2. It can be seen that the fragmentation pattern of lubricating oil can explain almost all the urban atmospheric organic material and that of fulvic acid can explain the fragmentation of the organic background. The gradual change in the organic mass spectral signature from urban to remote sites shown in Fig. 2, and the decreasing similarity with the lubricating oil spectra and increasing similarity with the fulvic acid spectra, as quantified in Table 2, provide clear evidence that atmospheric organic material gradually becomes more highly oxygenated moving away from source regions.

This is strong evidence that a generic prepresentation of the background organic composition may not be unreasonable. Fulvic acid, one of the major model compounds derived from ${ }^{1} \mathrm{H}$ NMR analyses of the ambient impactor samples gives a consistent and characteristic fragmentation pattern in the AMS which is close to that representing a very large part of the mass loading in background air. It must be stressed that the analysis does not suggest that fulvic acid is a major component of background atmospheric aerosol, but that the organic ions formed through volatilisation and ionisation of ambient aerosol in the AMS are similar to those observed when sampling fulvic acid. Together with the functional group analyses suggesting that, in all locations there are significant similarities in the relative proportion of oxidised functional groups, the AMS analysis suggests that a single representation capturing the functionality and behaviour of this mixture may be possible.

\section{Use of TORCH data to investigate the relationship between particulate organic behaviour and the oxidising environment:}

If there is significant processing of the organic aerosol component or significant addition of organic condensable material moving away from urban source regions, it might be expected that the composition and behaviour will depend on the exposure of the aerosols to an oxidising environment. The linear covariance of the ratio of $m / z 44 /$ total measured aerosol organic with gas phase organic species concentration has been found to be greatest for compounds such as carbonyls whose major sources are gas phase oxidation, ${ }^{56}$ reducing in magnitude for compounds with both primary emission and oxidation sources and showing significant anticorrelation with gas phase hydrocarbons with only direct emission as a source. Moreover, the opposite trend was observed for the covariances of the ratio of $\mathrm{m} / \mathrm{z} 57 /$ total measured aerosol organic with the same species. This directly supports the representation of the organic aerosol as one emission-driven and one oxidation-driven component. In addition, it has been found that, ${ }^{44}$ whereas the small organic mode, where present, correlated significantly with $\mathrm{CO}$ and $\mathrm{NO}_{x}$, the large mode was much more strongly correlated with PAN and $\mathrm{O}_{3}$. Furthermore, the shift to larger modal size corresponding to periods of higher ozone and lower $\mathrm{CO}$ was accompanied by the change in fragmentation spectrum to more closely resemble the representative background distribution.

We will now use data from the TORCH experiment to investigate in detail the changes in the aerosol behaviour with oxidising environment. During the experiment, three dominant categories of air mass were experienced. Ambient aerosol, when arriving at the site across London from a southwesterly direction, had less exposure to an oxidising environment since the major injection of emissions was more recent than when the stagnant air of European origin arrived at the site in the strong anticyclonic periods. Air arriving in trajectories originating from the Arctic had even greater potential exposure to atmospheric oxidation, but approached the measurement site with variable local wind direction with potential for local contributions to aerosol emissions. It is possible to obtain a measure of the integrated oxidation history of an air parcel by use of ratios of gaseous hydrocarbons of known common source profiles. ${ }^{60}$ Such hydrocarbon ratio data have been used to classify the air masses and segregate the measured data. Panel (b) in Fig. 10 shows the benzene/ toluene ratio (BTR) of each air mass classification with the range of expected photochemical age dependent on initial ratio and oxidant concentration in panel (a). 
(a)

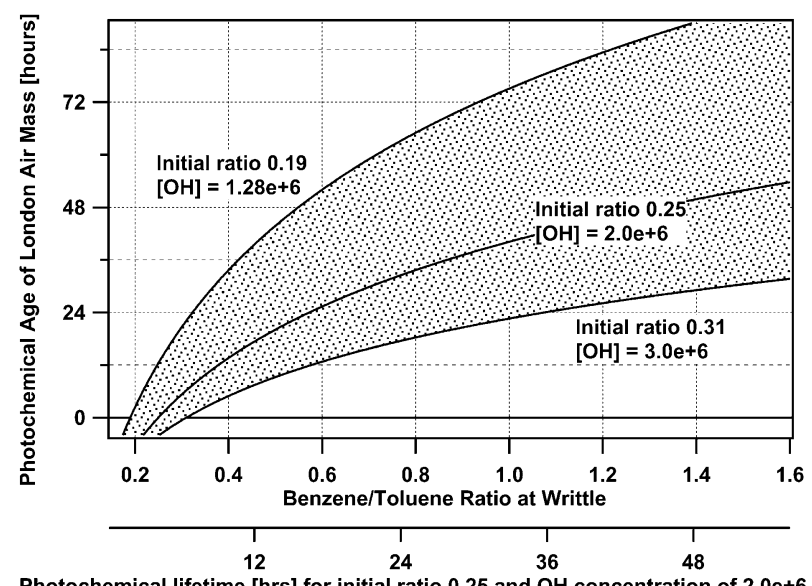

Photochemical lifetime [hrs] for initial ratio 0.25 and $\mathrm{OH}$ concentration of $2.0 \mathrm{e}+6$

(b)

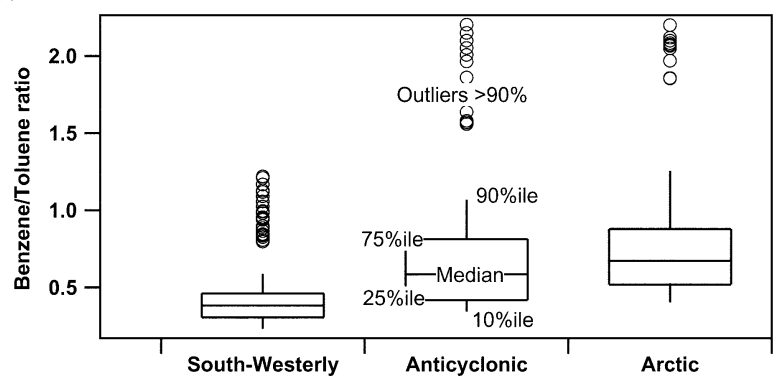

Fig. 10 (a) The photochemical age expressed as a function of the benzene/toluene ratio (BTR) for a range of hydroxyl radical concentrations and initial hydrocarbon ratios. (b) the range of BTR in each air mass classification during the TORCH 1 experiment.

Fig. 11 shows the difference in the average HTDMA hygroscopic diameter growth factor $\left(\mathrm{GF}_{\mathrm{D}}\right)$ of the aerosols to $90 \% \mathrm{RH}$ between the south westerly and anticyclonic periods. It can be seen that the south westerly aerosols are lower in $\mathrm{GF}_{\mathrm{D}}$ at all sizes than those arriving in anticyclonic air and that bimodality in the distributions from $60 \mathrm{~nm}$ to $137 \mathrm{~nm}$ showing the transition between a "less hygroscopic" (LH) and "more hygroscopic" (MH) mode is present only in the south westerly classification. At the smaller sizes, one might expect a greater contribution from combustionderived organic components in air masses more recently influenced by direct emissions. Such aerosols will be low in hygroscopicity and will fall into the LH mode. There will be a smaller contribution with increasing size due to the falloff in the size distribution of these directly emitted aerosols. In the more aged anticyclonic air, there are no LH particles. This is consistent with the picture of a background aerosol composition distribution appearing less influenced by recent emissions.

Using a recently developed ${ }^{59}$ analysis to attribute the relative contributions of the hydrocarbonlike to the oxygenated organic aerosol mass (that represented by the AMS fragmentation pattern described above), the contribution variation from a period of the TORCH 1 experiment is shown in Fig. 12. It can be seen that there is a large contribution of HOA during the south westerly period only and very little during the anticyclonic period. This is consistent with the expectation that the south westerly aerosols will have a signature similar to that found elsewhere (as detailed above) for recently emitted aerosols and that the anticyclonic organic component has a signature in a large part comparable to that attributed to the background oxygenated fraction identified previously.

To investigate how the aerosol population responds to the change in the oxidising history of the air parcel, the variability of the composition and hygroscopicity has been analysed in terms of 

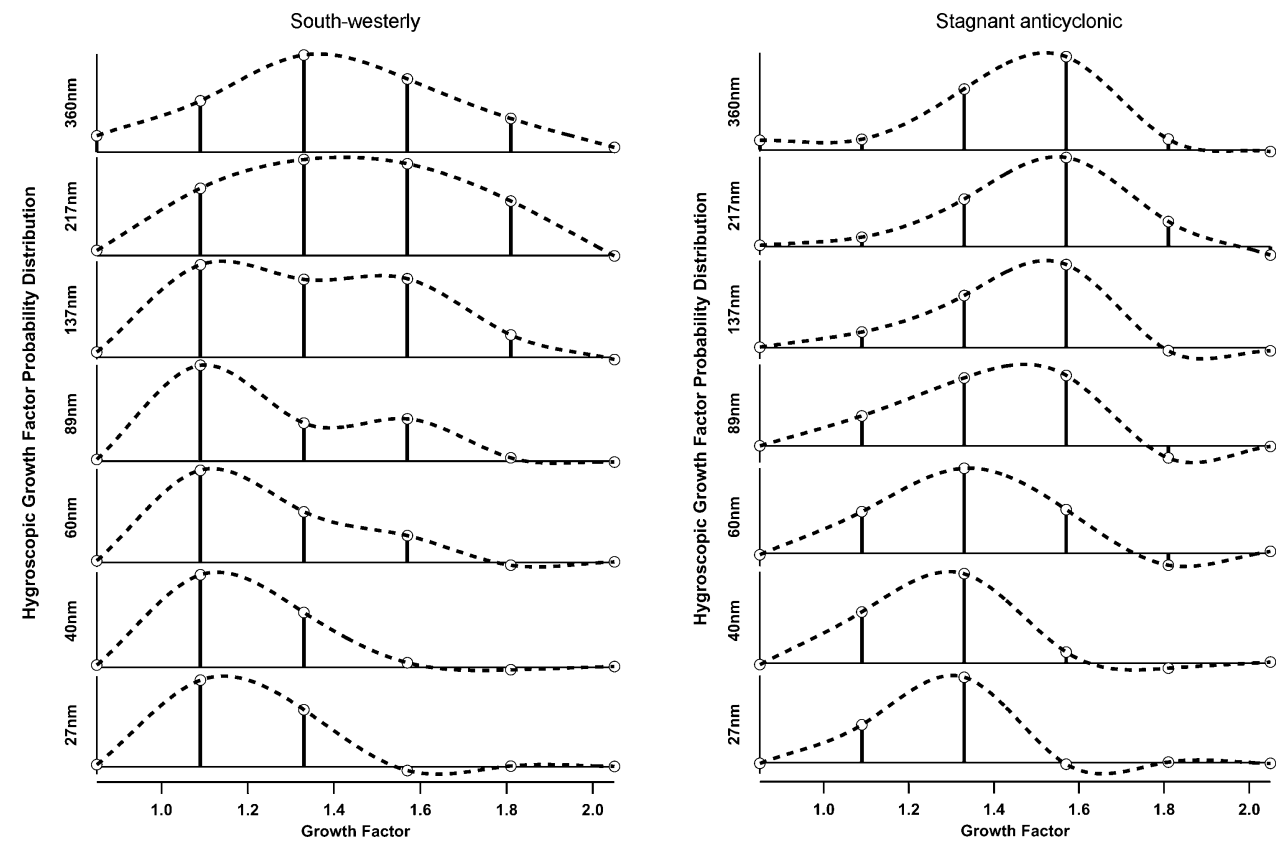

Fig. 11 Average HTDMA hygroscopic diameter growth factor $\left(\mathrm{GF}_{\mathrm{D}}\right)$ of the aerosols to $90 \% \mathrm{RH}$ for the south westerly and anticyclonic periods of the TORCH 1 experiment. The smaller particles from the south-westerly sector with most recent pollution input are in the less-hygroscopic (LH) mode. With increasing size, a bimodal hygroscopicity distribution is observed with some particles growing more at high humidity. At the largest size most particles are relatively soluble. During the anticyclonic period, when the air is photochemically more aged, the particles are more hygroscopic at all sizes than in south-westerly trajectories and increase in $\mathrm{GF}_{\mathrm{D}}$ with size.

the BTR. Fig. 13 shows the HOA fraction of the total organic aerosol mass plotted as a function of the BTR for each classification. As expected, the aerosol with the greatest contribution from HOA are in south westerly air masses with recent input of emissions from the London area. All measurements in this classification are at relatively young photochemical ages corresponding to BTR less than around 0.5 with the HOA contribution to the total organic aerosol loading reducing with increasing photochemical age. The stagnant air during the anticyclone carried aerosol of moderate fractional HOA loading, reducing to a base value of around 0.1 at BTR of around 0.5. With increasing photochemical age there was little change in the HOA contribution. The Arctic trajectories with local influence exhibited the greatest age and generally low contribution from HOA. It can be seen that the general trend is for the fractional contribution to the organic aerosol

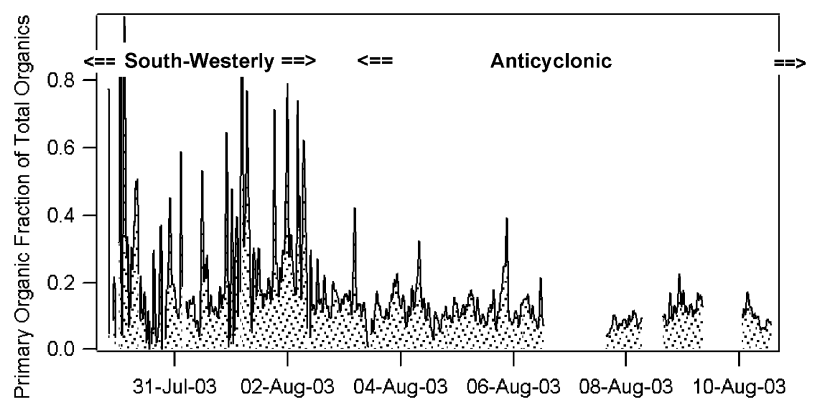

Fig. 12 The fraction of the total organic aerosol loading contributed by HOA over an airmass change during TORCH 1. The reduction in the contribution of HOA is apparent with the reduction in fresh pollution loading. 


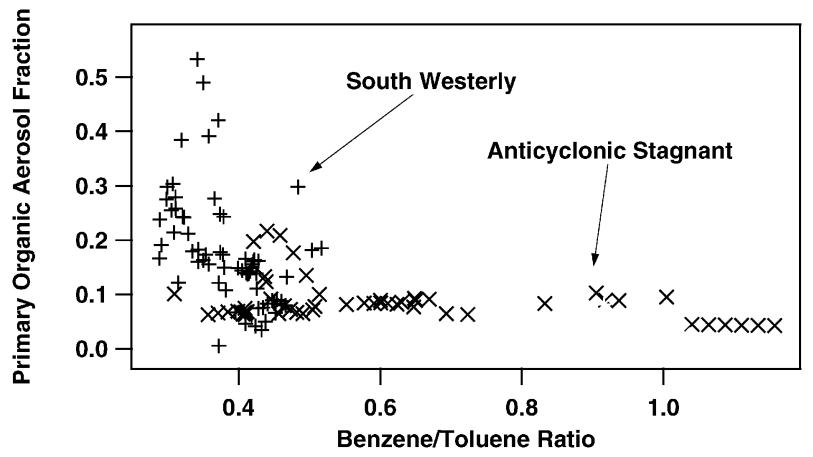

Fig. 13 HOA fraction of the total organic aerosol mass as a function of the BTR for each air mass classification during TORCH 1. When the photochemical age of an air mass is greater than that corresponding to a BTR of around 0.6 , there is no further reduction in the HOA contribution.

from HOA to reduce to a threshold value of around 0.1 at a BTR value of around 0.5 . This indicates that the HOA is largely lost from the aerosol in a timescale of between 12 and 36 hours (typically 20 h, see Fig. 10).

Averaging the HTDMA measurements over five ranges of BTR, it is possible to establish whether the photochemical age effect on growth factor behaviour corresponds to the effect on the changing HOA contribution to the organic aerosol fraction. Fig. 14 shows how the ambient aerosols in air masses of varying photochemical age respond to the moist atmosphere. The $27 \mathrm{~nm}$ dry diameter particles exhibit a single $\mathrm{GF}_{\mathrm{D}}$ mode increasing with increasing age from 1.1 to 1.35 with no further change above BTR of 0.8 . The $89 \mathrm{~nm}$ particles appear to have a LH mode at all photochemical ages,

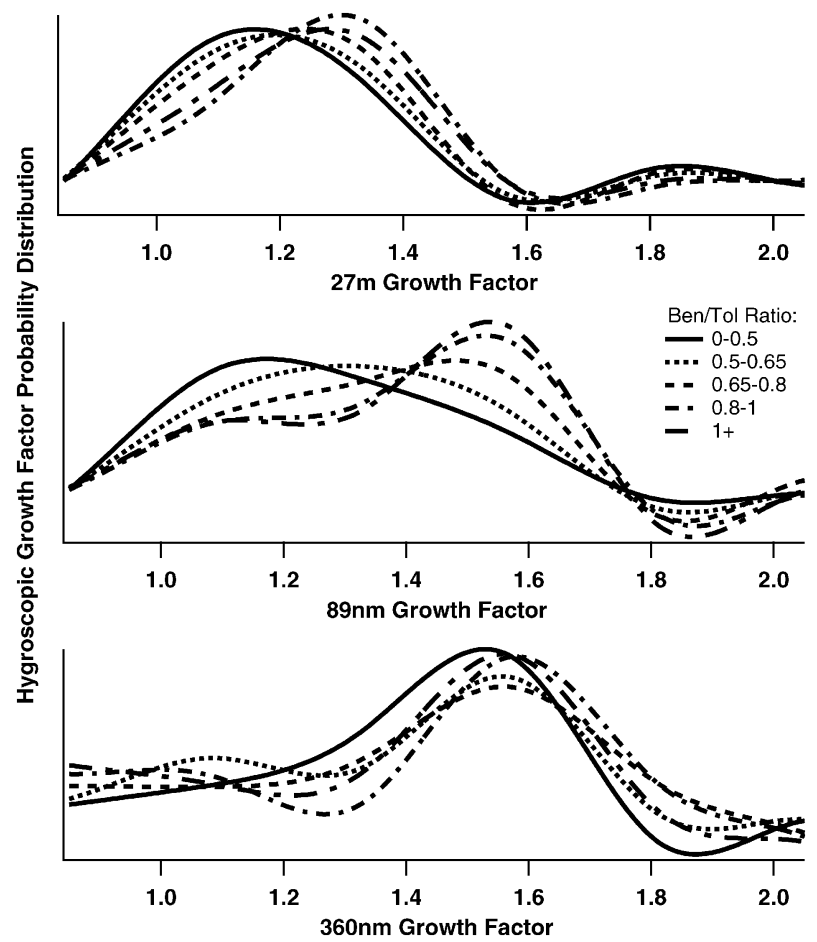

Fig. 14 Growth factor variation with varying photochemical age. The smallest, $27 \mathrm{~nm}$ diameter, particles (top panel) separate clearly into two modes, as do those at $89 \mathrm{~nm}$. The $360 \mathrm{~nm}$ particles are generally all fairly hygroscopic and may be considered to represent a "background" contribution in all air masses. 
with a second $\mathrm{MH}$ mode increasing in $\mathrm{GF}_{\mathrm{D}}$ from 1.1 to 1.55 with increasing age; a plateau again reached at BTR of 0.8 . The largest dry sized particles, at $360 \mathrm{~nm}$, have little or no LH mode and a $\mathrm{MH}$ mode which remains broadly constant at $\mathrm{GF}_{\mathrm{D}}$ around 1.55 to 1.6. In all cases the development of the MH mode has been complete by between 18 to $60 \mathrm{~h}$ (typically 30 hours, see Fig. 10).

The data suggest that the reduction of the HOA contribution to the aerosol organic fraction occurs on a similar timescale to, but probably slightly more rapidly than, the changes effecting the removal of the LH mode and development of the MH mode. We have already shown that the hygroscopicity of the particulates is dominated by the inorganic components. This is further evidence that, though the hygroscopicity and the nature of the organic fraction both change with photochemical age of the air mass, the change in the organic fraction is unlikely to directly cause of the change in the aerosol behaviour in the moist atmosphere.

\section{Conclusions}

We have shown that inorganic component changes must be responsible for any increase in hygroscopicity with photochemical ageing - the water affinity of even the most oxidised organic components is insufficient to contribute greatly to hygroscopicity of aged aerosols. It is therefore likely that the changes in hygroscopicity as a function of photochemical age arise from the gaseous photochemical production of condensable inorganic acids or from the aqueous production of such compounds, either in- or out-of-cloud. The accumulation and of condensed organic material with age will increase the dry mass of the particle, but will not add significantly to the water uptake. This will lead to an apparent reduction in hygroscopicity of the particle, but evidence suggests that this is more than offset by the increase in inorganic material.

If the photochemical transformation lifetimes measured during the TORCH experiment are representative, the change in organic characteristics and in particulate hygroscopicity, though not necessarily related, will happen in around one day. This is generally within a single cell in global models at representative boundary layer wind speeds.

A single representation of nearfield and background organic aerosol composition is sufficient to describe the AMS fragmentation pattern observed in a variety of field experiments including the TORCH experiment. The nearfield small mode organics are dominated by a combustion-derived unoxidised signature, whilst the background accumulation mode is more oxygenated and dominates in air masses with a photochemical age of more than a couple of days. It must be established to what extent this representation is the result of oxidative production of condensable precursors, condensed phase organic oxidation or simply the associated dilution of urban-derived particles into the background population.

This representation may be used within the sub-saturated regime to predict the behaviour of ambient particulates in the moist atmosphere due to the insensitivity of hygroscopicity to the contribution from organic material. For the northern mid-latitude continentally influenced environment for which we currently have measurements the organic fraction contributes little to water uptake by the aerosol, which is dictated almost entirely by the inorganic components. The organic fraction has been shown to have a growth factor of only 1.11 for two different sets of model compounds; the growth is dictated by the fractional mass loading of the inorganic and organic components and this is the parameter which must be captured accurately in large-scale models. At present, there is insufficient data to ascertain whether this simplification can be more widely interpreted. Further measurements and analyses are required to determine if the conclusions are valid across all environments of this type or whether they can be carried forward to simplify the interpretation of the hygroscopic behaviour of mixed organic-inorganic aerosol systems in other or all ambient atmospheric environments.

This approach also needs to be extended to explore whether there is a significant effect of the change in organic character on other important aspects of aerosol behaviour such as changes in optical properties or cloud activation under supersaturation. It may be expected that the contribution of organic compounds will increase on approaching saturation due to their effect on surface tension suppression. In addition, the simple representation of a vast range of organic compounds does not facilitate linkage to gaseous precursors. However, if complex behaviour can be simplified using these techniques or similar ones and parameterised in efficient ways, such as linking to 
photochemical age, then global representation of complex aerosol composition and prediction of subsequent behaviour may be possible.

\section{Glossary}

\begin{tabular}{ll}
\hline ADDEM & Aerosol Diameter Dependent Equilibrium Model \\
AMS & Aerodyne Aerosol Mass Spectrometer \\
BTR & Ambient benzene/toluene ratio \\
CPC & Condensation particle counter \\
DMA & Differential mobility analysers \\
DMPS & Differential mobility particle sizer \\
EC & Elemental carbon \\
FSSP-100 & Forward Scattering Spectrometer Probe \\
GF & Hygroscopic diameter growth factor diagnosed by HTDMA \\
${ }^{1}$ H NMR & Proton nuclear magnetic resonance \\
HTDMA & Hygroscopicity tandem differential mobility analyser \\
HOA & Hydrocarbon-like organic aerosol \\
HULIS & Humic-like substances \\
LH & Less hygroscopic ambient particle mode diagnosed by HTDMA \\
MDA & Mono- and di-acidic grouping of WSOC \\
MH & More hygroscopic ambient particle mode diagnosed by HTDMA \\
MS & Mass-spectrum operational mode of the AMS \\
NC & Neutral compound grouping of WSOC \\
OOA & Oxygenated organic aerosol \\
OPC & Optical particle counter \\
PA & Polyacidic compound grouping of WSOC \\
PM 1.0 & Mass of particulate material of diameter less than 1 micrometre \\
SMPS & Scanning mobility particle sizer \\
TOC & Total organic carbon \\
ToF & Aerosol time-of-flight operational mode of the AMS \\
TORCH & UK NERC-funded Tropospheric ORganic CHemistry project \\
\end{tabular}

\section{References}

1 M. R. Alfarra, H. Coe, J. D. Allan, K. N. Bower, H. Boudries, M. R. Canagaratna, J. L. Jimenez, J. T. Jayne, A. Garforth, S. Li and D. R. Worsnop, Atmos. Environ., 2004, 38, 5745.

2 H. A. Gray, G. R. Cass, J. J. Huntzicker, E. K. Heyerdahl and J. A. Rau, Environ. Sci. Technol., 1986, 20, 580 .

3 W. F. Rogge, M. A. Mazurek, L. M. Hildemann, G. R. Cass and B. R. T. Simoneit, Atmos. Environ., 1993, 27, 1309.

4 A. M. Middlebrook, D. M. Murphy and D. S. Thomson, J. Geophys. Res., 1998, 103, 16475.

5 J. C. Chow, J. G. Watson, E. M. Fujita, Z. Q. Lu, D. R. Lawson and L. L. Ashbaugh, Atmos. Environ., 1994, 28, 2061

6 S. Decesari, M. C. Facchini, S. Fuzzi and E. Tagliavini, J. Geophys. Res., 2000, 105, 1481.

7 Climate Change 2001: The Scientific Basis, ed. J. T. Houghton, Y. Ding, D. J. Griggs, M. Noguer, P. J. van der Linden and D. Xiaosu, Cambridge University Press, Cambridge, 2001.

8 C. A. Pope III, Aerosol Sci. Technol., 2000, 32, 4.

9 M. O. Andreae and P. J. Crutzen, Science, 1997, 276, 1052.

10 M. C. Jacobson, H. C. Hansson, K. J. Noone and R. J. Charlson, Rev. Geophys., 2000, 38, 267.

11 P. Saxena and L. M. Hildemann, Environ. Sci. Technol., 1997, 31, 3318.

12 M. C. Facchini, S. Decesari, M. Mircea, S. Fuzzi and G. Loglio, Atmos. Environ., 2000, 34, 4853.

13 C. G. Peng and C. K. Chan, Atmos. Environ., 2001, 35, 1183.

14 H. Puxbaum, J. Rendl, R. Allabashi, L. Otter and M. Scholes, J. Geophys. Res., 2000, 105, 697.

15 N. Havers, P. Burba, J. Lambert and D. Klockow, J. Atmos. Chem., 1998, 29, 45.

16 M. C. Facchini, S. Fuzzi, S. Zappoli, A. Andracchio, A. Gelencser, G. Kiss, Z. Krivacsy, E. Meszaros, H.-C. Hansson, T. Alsberg and Y. Zebuhr, J. Geophys. Res., 1999, 104, 26821. 
17 S. Zappoli, A. Andracchio, S. Fuzzi, M. C. Facchini, A. Gelencser, G. Kiss, Z. Krivacsy, A. Molnar, E. Meszaros and H.-C. Hansson, Atmos. Environ., 1999, 33, 2733.

18 Z. Krivacsy, G. Kiss, B. Varga, I. Galambos, Z. Sarvari, A. Gelencser, A. Molnar, S. Fuzzi, M. C. Facchini and S. Zappoli, Atmos. Environ., 2000, 34, 4273.

19 Z. Krivacsy, A. Hoffer, Z. Sarvari, D. Temesi, U. Baltensperger, S. Nyeki, E. Weingartner, S. Kleefeld and S. G. Jennings, Atmos. Environ., 2001, 35, 6231.

20 A. Limbeck, M. Kulmala and H. Puxbaum, Geophys. Res. Lett., 2003, 30, DOI: 10.1029/2003GL017738.

21 M. Kalberer, D. Paulsen, M. Sax, M. Steinbacher, J. Dommen, A. S. H. Prevot, R. Fisseha, E. Weingartner, V. Frankevich, R. Zenobi and U. Baltensperger, Science, 2004, 303, 1659.

22 M. P. Tolocka, M. Jang, J. M. Ginter, F. J. Cox, R. M. Kamens and M. V. Johnston, Environ. Sci. Technol., 2004, 38, 1428.

23 H. Mukai and Y. Ambe, Atmos. Environ., 1986, 20, 813.

24 Q. Zhang and C. Anastasio, Atmos. Environ., 2003, 37, 2247.

25 D. J. Rader and P. H. McMurry, J. Aerosol Sci., 1986, 17, 771.

26 M. Cubison and H. Coe, J. Aerosol. Sci., 2004, 35.

27 M. L. Pitchford and P. H. McMurry, Atmos. Environ., 1994, 28, 827.

28 P. Saxena, L. M. Hildemann, P. H. Mcmurry and J. H. Seinfeld, J. Geophys. Res., 1995, 100, 18755.

29 M. Y. Choi and C. K. Chan, J. Phys. Chem. A, 2002a, 106, 4566.

30 H. S. Na, S. Arnold and A. S. Myerson, J. Cryst. Growth, 1995, 149, 229.

31 A. J. Prenni, P. J. DeMott, S. M. Kreidenweis, D. E. Sherman, L. M. Russell and Y. Ming, J. Phys. Chem. $A, 2001, \mathbf{1 0 5}, 11240$.

32 M. Y. Choi and C. K. Chan, Environ. Sci. Technol., 2002b, 36, 2422.

33 C. N. Cruz and S. N. Pandis, Environ. Sci. Technol., 2000, 34, 4313.

34 J. M. Lightstone, T. B. Onasch, D. Imre and S. Oatis, J. Phys. Chem. A, 2000, 104, 9337.

35 S. D. Brooks, P. J. DeMott and S. M. Kreidenweis, Atmos. Environ., 2004, 38, 1859.

36 E. Mikhailov, S. Vlasenko, R. Niessner and U. Poeschl, Atmos. Chem. Phys., 2004, 4, 323.

37 D. O. Topping, G. McFiggans and H. Coe, Atmos. Chem. Phys. Discuss., 2004, submitted.

38 D. O. Topping, G. McFiggans and H. Coe, Atmos. Chem. Phys. Discuss., 2004, submitted.

39 W. Winklmayr, G. P. Reischl, A. O. Lindner and A. Berner, J. Aerosol. Sci., 1991, 22, 289.

40 J. T. Jayne, D. C. Leard, X. F. Zhang, P. Davidovits, K. A. Smith, C. E. Kolb and D. R. Worsnop, Aerosol Sci. Technol., 2000, 33, 49.

41 J. D. Allan, M. R. Alfarra, K. N. Bower, P. I. Williams, M. W. Gallagher, J. L. Jimenez, A. G. McDonald, E. Nemitz, M. R. Canagaratna, J. T. Jayne, H. Coe and D. R. Worsnop, J. Geophys. Res., 2003, $108,4091$.

42 J. L. Jimenez, J. T. Jayne, Q. Shi, C. E. Kolb, D. R. Worsnop, I. Yourshaw, J. H. Seinfeld, R. C. Flagan, X. Zhang, K. A. Smith, J. W. Morris and P. Davidovits, J. Geophys. Res., 2003, 108, 8425.

43 F. Drewnick, J. T. Jayne, M. R. Canagaratna, D. R. Worsnop and K. L. Demerjian, Aerosol Sci. Technol., 2004, 38, 104.

44 M. R. Alfarra, H. Coe, J. D. Allan, K. N. Bower, H. Boudries, M. R. Canagaratna, J. L. Jimenez, J. T. Jayne, A. Garforth, S. Li and D. R. Worsnop, Atmos. Environ., 2004, 38, 5745.

45 A. Berner and C. Lurzer, J. Phys. Chem., 1980, 84, 2079.

46 D. O. Topping, D. O. H. Coe, G. McFiggans, R. A. Burgess, J. D. Allan, M. R. Alfarra, K. N. Bower, T. W. Choularton, S. Decesari and M-C. Facchini, Atmos. Environ., 2004, 38, 2111.

47 S. Decesari, M. C. Facchini, S. Fuzzi, G. McFiggans, H. Coe and K. N. Bower, Atmos. Environ., 2005, 39, 211.

48 S. L. Clegg, J. H. Seinfeld and P. Brimblecombe, J. Aerosol Sci., 2001, 32, 713.

49 Y. Ming and L. M. Russell, AIChE J., 2002, 48, 1331.

50 S. L. Clegg and K. S. Pitzer, J. Phys. Chem., 1992, 96, 3513.

51 S. L. Clegg, K. S. Pitzer and P. Brimblecombe, J. Phys. Chem., 1992, 96, 9470.

52 A. Fredenslund, R. L. Jones and J. M. Prausnitz, AIChE J., 1975, 21, 1086.

53 C. Peng, M. N. Chan and C. K. Chan, Environ. Sci. Technol., 1998, 35, 4495.

54 R. H. Stokes and R. A. Robinson, J. Phys. Chem., 1966, 70, 2126.

55 H. Boudries, M. R. Canagaratna, J. T. Jayne, M. R. Alfarra, J. D. Allan, K. N. Bower, H. Coe, S. C. Pryor, J. L. Jimenez, J. R. Brook, S. Li and D. R. Worsnop, Atmos. Environ., 2004, 38, 5759.

56 J. D. Allan, K. N. Bower, H. Coe, H. Boudries, J. T. Jayne and D. R. Worsnop, J. Geophys. Res., 2004, 109, DOI: $10.1029 / 2003 J D 004208$.

57 M. R. Canagaratna, J. T. Jayne, D. A. Ghertner, S. Herndon, Q. Shi, J. L. Jimenez, P. J. Silva, P. Williams, T. Lanni, F. Drewnick, K. L. Demerjian, C. E. Kolb and D. R. Worsnop, Aerosol Sci. Technol., 2004, 38, 555.

58 F. W. McLafferty and F. Turecek, Interpretation of Mass Spectra, University Science Books, Herndon, VA, 4th edn., 1993.

59 Q. Zhang, M. R. Alfarra, D. R. Worsnop, J. D. Allan, H. Coe, M. R. Canagaratna and J. L. Jimenez, Environ. Sci. Technol., 2004, submitted.

60 D. D. Parrish, C. J. Hahn, E. J. Williams, E. B. Norton, F. C. Fehsenfeld, H. B. Singh, J. D. Shetter, B. W. Gandrud and B. A. Ridley, J. Geophys. Res., 1992, 103, 22339. 